Estudios sobre armas antiguas, arte militar y vida cultural en oriente y occidente

XLI (2021), pp. 91-119

ISSN: 0436-029X; eISSN: 1988-4168

https://doi.org/10.3989/gladius.2021.05

\title{
EL CONJUNTO DE CAMPAMENTOS ROMANOS PARA PRÁCTICAS DE TROBAJO DEL CAMINO (SAN ANDRÉS DE RABANEDO) Y OTERUELO DE LA VALDONCINA (LEÓN). UNA APROXIMACIÓN PRELIMINAR*
}

\author{
ROMAN PRACTICE CAMPS AT TROBAJO DEL CAMINO (SAN ANDRÉS DE RABANEDO) \\ AND OTERUELO DE LA VALDONCINA (LEÓN). A PRELIMINARY APPROACH
}

\author{
POR \\ Ángel Morillo* ${ }^{* *}$ Brais X. Currás ${ }^{* * *}$, Almudena Orejas A $^{* * * *}$ \\ y Agostino NoBILINI ${ }^{* * * * *}$
}

\section{RESUMEN - AbSTRACT}

La investigación mediante métodos de teledetección del territorio del campamento de Legio (León) ha llevado a identificar casi una veintena de recintos militares romanos. Una primera aproximación permite interpretarlos como campamentos para prácticas, dispuestos en una plataforma llana y bien nivelada, con un gran dominio visual sobre el valle del Bernesga, y organizados en torno a la vía romana que se dirigía hacia Asturica. Los recintos, algunos de ellos conservados parcialmente, presentan diferentes orientaciones pero todos ellos comparten la típica planta campamental rectangular con esquinas redondeadas. A la espera de avances en el trabajo de campo, todo parece indicar que se trata de recintos de época imperial para prácticas de castrametación. Se conocen varios conjuntos de este tipo en el Imperio, especialmente en las provincias septentrionales.

Research based on remote sensing methods developed in the territory of the legionary fortress at Legio (León) has allowed the identification of about twenty small Roman military forts. An initial investigation leads us to propose that they are practice camps, arranged on a flat plateau, with excellent visibility over the river Bernesga valley. The camps are located on either side of the Roman road from Legio (León) to Asturica (Astorga). Some of these practice camps are only partially preserved, they display different orientations but all of them share the typical rectangular Roman camp plan with rounded corners. Pending future verification on the ground, they can be suggested as being Early Imperial forts for military entrenchment training. Several similar groups of installations are known throughout the Empire, especially in the northern provinces.

* Este trabajo se inscribe dentro del Proyecto de Investigación "Paisaje y territorio militarizado en la Hispania romana: movilidad y transferencia cultural (ss. II a. C. - IV d. C.) (MILITRANSFER)" (I+D HAR2017-85929-P), concedido para el periodo 2018-2021 por el Ministerio de Economía, Industria y Competitividad (MINECO), a la Agencia Estatal de Investigación (AEI) y al Fondo Europeo de Desarrollo Regional (FEDER), cuyos investigadores principales son Ángel Morillo y Cruces Blázquez Cerrato, del Proyecto de Investigación "Economías locales, economía imperial: el occidente de la Península Ibérica (siglos II a. C. al II d. C.), LOKI" (PID2019-104297GB-100) ), cuya investigadora principal es Inés Sastre Prats, y del PIE "Paisajes culturales en el norte y noroeste de la Península Ibérica: territorios urbanos, agrarios y mineros, NyNO" (202010E147), cuya investigadora principal es Almudena Orejas Saco del Valle. Queremos agradecer las valiosas sugerencias de los evaluadores anónimos de este trabajo, así como el apoyo de la Dirección General de Patrimonio de la Junta de Castilla y León y su Servicio de Planificación, Investigación y Difusión.

${ }_{* *}^{*}$ Universidad Complutense de Madrid, amorillo@ucm.es / ORCID iD: https://orcid.org/0000-0003-2139-0346

*** Instituto de Historia, CSIC, brais.curras@cchs.csic.es / ORCID iD: https://orcid.org/0000-0002-8975-070X

***** Instituto de Historia, CSIC, almudena.orejas@cchs.csic.es / ORCID iD: https://orcid.org/0000-0003-4675-2489

****** Universidad Complutense de Madrid, agostinonobilini@yahoo.it / ORCID iD: https://orcid.org/0000-0001-8631-6089 


\section{Palabras Clave - Keywords}

Arqueología militar; León/Legio; campamentos romanos; campamentos para prácticas; teledetección; LiDAR. Roman Military Archaeology; León/Legio; Roman Camps; practice camps; remote sensing methods; LiDAR.

\section{Cómo CitAR eSte ARTículo / CitATion}

Morillo, Á.; Currás, B. X.; Orejas, A. y Nobilini, A. (2021): «El conjunto de campamentos romanos para prácticas de Trobajo del Camino (San Andrés de Rabanedo) y Oteruelo de la Valdoncina (León). Una aproximación preliminar». Gladius, 41: 91-119. https://doi.org/10.3989/gladius.2021.05

RECIBIDO / RECEIVED: 27-05-2020

ACEPTADO / ACCEPTED: 23-02-2021

Los campamentos romanos, tanto de carácter temporal como permanente, generan en torno a ellos procesos particulares de territorialización y dan lugar a paisajes de ocupación y explotación económica, muy diferentes a los surgidos en las civitates y adscritos jurisdiccionalmente a la unidad militar ocupante. Dentro de los territorios militares cada vez se perfila más la actuación e influencia del ejército asentado en la región, en forma de guarniciones, organización de espacios y poblaciones, explotación de recursos básicos, importación de manufacturas itálicas, modas y usos castrenses, etc. Dentro de los proyectos de $\mathrm{I}+\mathrm{D}$ que vienen desarrollándose en los últimos 10 años bajo la dirección de uno de los firmantes (A. Morillo), el territorio de León, base de las legiones VI victrix y VII gemina a lo largo del Imperio, ha recibido una atención especial, teniendo como objetivo principal profundizar en las formas de ocupación del espacio por parte del ejército romano ${ }^{1}$. Durante las labores iniciadas de recopilación de información documental y prospección de algunos municipios del entorno de la capital leonesa, centrados particularmente en el trazado viario, hace unos años se descubrió un posible recinto militar en Trobajo del Camino, en el término municipal de San Andrés de Rabanedo. La localización del mismo ha permitido ampliar la búsqueda en el entorno y

\footnotetext{
${ }^{1}$ Debemos mencionar el Proyecto: "Campamentos y Territorios militares en Hispania” (MINECO I+D HAR201124095), junto a los citados más arriba, así como el apoyo del convenio de investigación: Los campamentos romanos de las legiones VI victrix y VII gemina en León. Estudio del material arqueológico procedentes de las excavaciones arqueológicas en la ciudad de León, en el marco del Plan PAHIS 2004-2012 del Patrimonio Histórico de Castilla y León, dirigido por Ángel Morillo.
}

la identificación de nuevas evidencias mediante sistemas de teledetección tanto en esta localidad como en Oteruelo de la Valdoncina, adscrito al término municipal de León, cuya primera aproximación presentamos en este trabajo ${ }^{2}$.

El conjunto se compone por las evidencias de hasta 18 posibles recintos castrenses documentados mediante teledetección (Fig. 1). Se encuentran a $4 \mathrm{~km}$ en línea recta del lugar ocupado por los campamentos sucesivos de la legio VI victrix y de la legio VII gemina, bajo el actual casco urbano de León, coincidente con el recinto amurallado bajoimperial, y en una cota 30-40 m superior a la de este.

Los recintos campamentales presentan, en todos los casos, la típica planta cuadrangular-generalmente rectangular y excepcionalmente cuadra$\mathrm{da}-\mathrm{y}$ con las esquinas redondeadas, que aunque aparece con anterioridad, se generaliza desde mediados del siglo I d. C. Las estructuras se sitúan sobre la plataforma formada por los niveles intermedios de las terrazas de origen cuaternario de la margen derecha del río Bernesga, en una superficie llana, bien nivelada, que se alza $40 \mathrm{~m}$ sobre la llanura de inundación.

Las evidencias componen un conjunto compacto, estructurado de norte a sur, que aprovecha la mayor parte de la superficie llana de la terraza y que se sitúa invariablemente en torno a los 870 $\mathrm{m}$ de cota (Fig. 2). Tan solo las estructura R-7 y R-18 rompen con esta pauta, con una localiza-

\footnotetext{
2 Todo ello forma parte de una tesis doctoral actualmente en curso, desarrollada por A. Nobilini, uno de los firmantes de este trabajo, realizada bajo la dirección de A. Morillo y A. Orejas. Al equipo de investigación se ha sumado B. Curras, miembro de los mencionados proyectos de investigación (I+D HAR2017-85929-P y HAR2015-64632-P).
} 


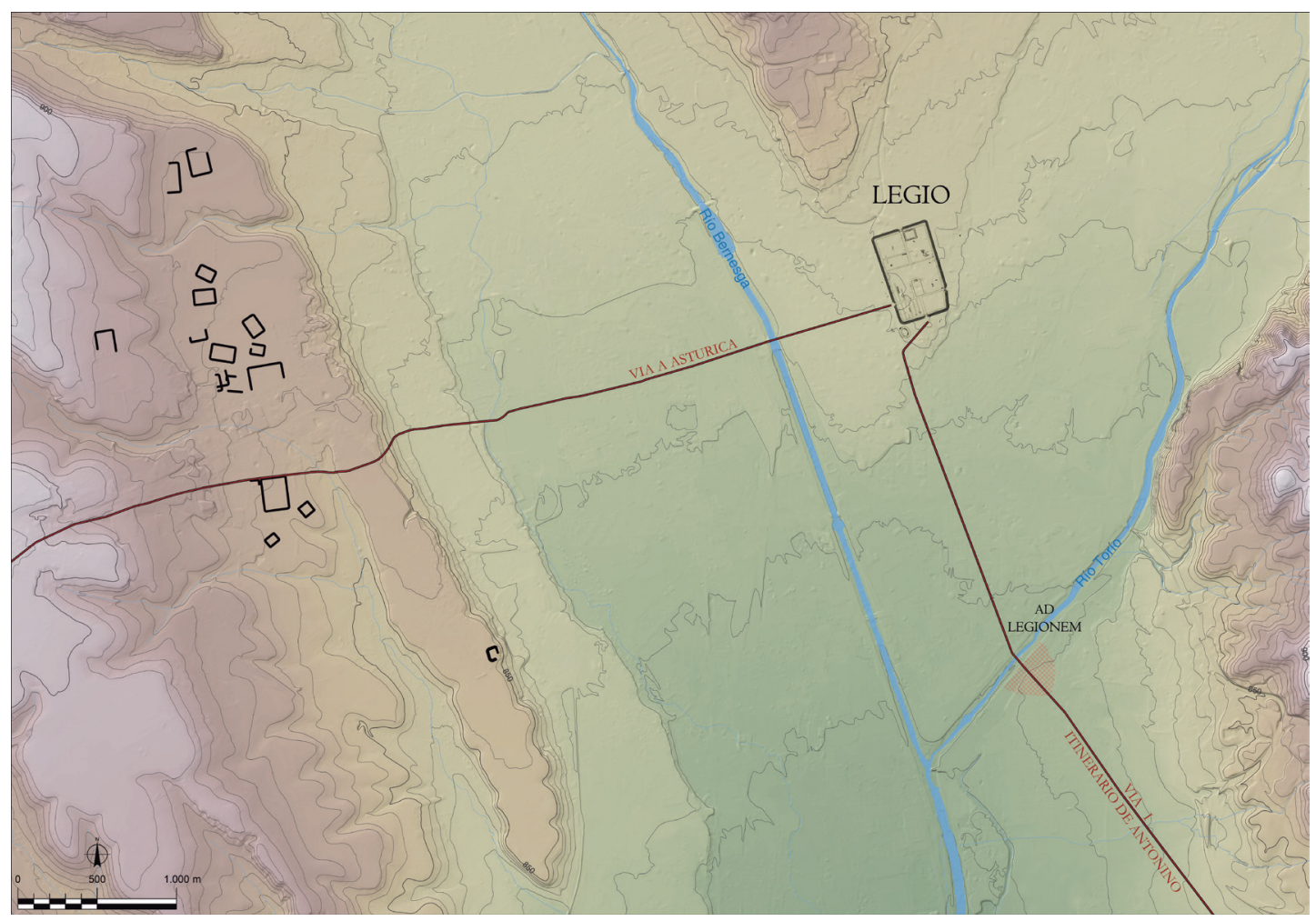

Figura 1. Posición del conjunto de Trobajo del Camino/Oteruelo de la Valdoncina sobre la confluencia de los ríos Bernesga y Torío.

ción ligeramente excéntrica respecto al conjunto y a una cota algo más elevada. Los recintos se disponen formando tres agrupaciones, separadas por pequeñas vaguadas que atraviesan la terraza transversalmente. El conjunto más septentrional lo componen los recintos R-5 y R-6. Hacia el sur, separado por el arroyo de Santiago, aparece el conjunto central constituido por los recintos $\mathrm{R}-1,2,3,4,8,9,10,11,12$ y 13. El grupo meridional, integrado por los recintos $\mathrm{R}-14,15,16 \mathrm{y}$ 17 , queda separado por la vaguada que forma el arroyo de Las Fontanillas y el denominado Camino de la Raya, límite del término municipal de León. En la actualidad, la topografía muestra un espacio allanado entre los conjuntos central y meridional, que originalmente estaría ocupado por una vaguada, hoy desaparecida bajo la gran transformación que supuso el trazado de la nueva carretera y la construcción de un polígono industrial.

Esta ocupación sistemática de la plataforma no parece responder a un patrón ordenado sincrónico, ya que hay superposiciones y orientaciones diversas. Sin embargo, como luego se verá, sí res- ponden a una lógica. Efectivamente, se constata una orientación divergente de las estructuras -con la única excepción de la disposición paralela de los contiguos R-14 y R-15- e incluso la superposición de los recintos R-10, R-11 y R-12, que demuestra la existencia de una, quizás mínima, diacronía en su construcción.

Por tanto, detrás del conjunto castrense de Trobajo del Camino/Oteruelo de la Valdoncina se puede leer una misma decisión locacional, basada en la elección de un tipo de emplazamiento muy concreto, que justifica la concentración en él de los recintos. Puede considerarse como la materialización de un tipo de actividad militar que genera un patrón de recurrencia ocupacional discontinua, a lo largo de un periodo indeterminado $^{3}$.

\footnotetext{
${ }^{3}$ Teniendo en cuenta que la parte principal del conjunto se encuentra en la localidad de Trobajo del Camino, perteneciente a San Andrés de Rabanedo, y a fin de no estar reiterando a lo largo del texto que parte del mismo está en otro término municipal, nos referiremos al conjunto de forma genérica como de "San Andres de Rabanedo" o "Trobajo del Camino".
} 


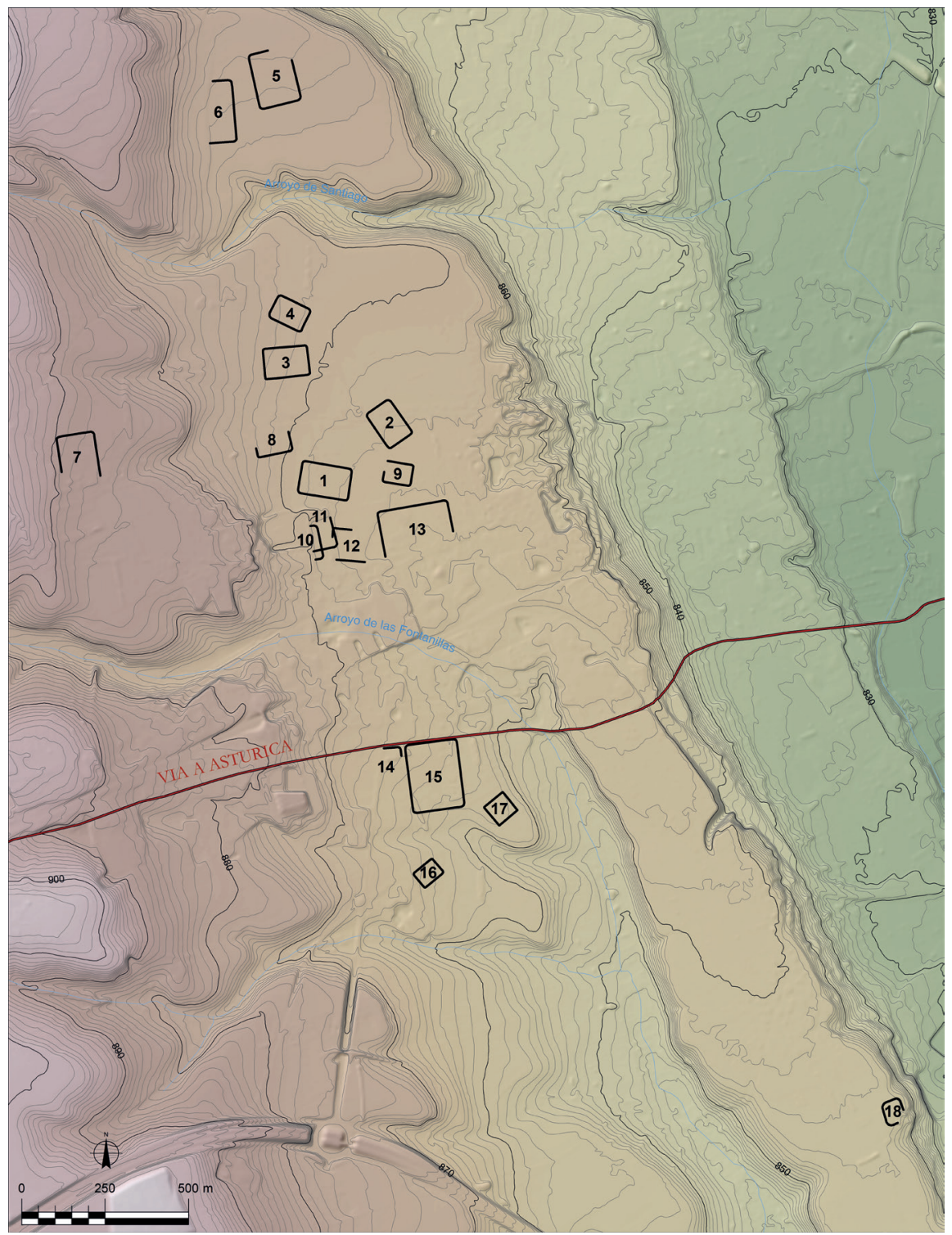

Figura 2. Vista general del conjunto de Trobajo del Camino/Oteruelo de la Valdoncina.

\section{METODOLOGÍA}

Los medios de teledetección son una herramienta fundamental en la documentación y el estudio de las evidencias campamentales del proceso de conquista y control del territorio en época romana, sobre todo en aquellas estructuras de carácter provisional y efímero propias de los campamentos de marcha o de campaña, que apenas presentan materiales, ni restos estructurales identificables fácilmente sobre el terreno mediante prospección (Morillo, 2008: 74-76; Morillo et alii, 2020). La fotografía aérea, como base sobre la que se han desarrollado múltiples trabajos de estudio del territorio, ha sido clave en la arqueología militar en la identificación y el estudio de campamentos en el noroeste peninsular (Loewinsohn, 1965; Didierjean et alii, 2014), surgiendo una metodología ya perfectamente empleada desde los años sesenta del siglo pasado en otras regiones fronterizas del Imperio (Scollar, 1965) ${ }^{4}$.

4 No podemos dejar de mencionar a los pioneros del empleo de la fotografía aérea en Arqueología, que ya utilizaron 
El desarrollo de la tecnología LiDAR y el avance de los medios de análisis formal del territorio de la última década ha repercutido además muy positivamente en la documentación de las estructuras campamentales antiguas (Sánchez-Palencia y Currás, 2015; Costa et alii, 2016; Cordero et alii, 2017), lo que ha permitido avanzar significativamente respecto a lo que ya constituía una línea de investigación muy novedosa en España desde finales del siglo XX (p. e. Orejas y Sánchez Palencia, 1999; Morillo, 1991 y 2002).

Las evidencias de los recintos que constituyen el conjunto de Trobajo del Camino son marcas en el suelo originadas por el crecimiento diferencial de la vegetación, causado por estructuras en el subsuelo (crop marks y soil marks). Este es uno de los clásicos sistemas de teledetección de restos antiguos, construidos o excavados (Wilson, 1982; Picarreta, 1987; Orejas, 1995; Opitz y Cowley, 2012). El estudio secuencial de la fotografía aérea ha permitido detectar, identificar y fotointerpretar las trazas sobre el terreno, delimitando los recintos. Se trata de estructuras negativas, que aparecen en la imagen en forma de manchas de mayor intensidad, resultado de un crecimiento de la vegetación más vigoroso. En las imágenes de falso color infrarrojo, sobre todo en el vuelo del PNOA de 2011, se detectan gracias a un rojo más intenso. Estas improntas se corresponden con los fosos (fossae), que crean cubetas artificiales, con una retención de humedad superior a la del entorno.

El suelo de la terraza sobre la que se sitúan los recintos es de matriz arenosa, con un elevado contenido de cantos y gravas, fundamentalmente de tipo cuarcítico (Rodríguez Fernández y Heredia, 2005). Son suelos ligeros, de poco espesor y limitada capacidad de enraizamiento, que han sido empleados históricamente como tierras de cultivo de secano dedicadas al cereal. Las antiguas tierras de labor se encuentran en la actualidad abandonadas, ocupadas por una vegetación rala, compuesta

estos documentos en la identificación y documentación de estructuras castrenses, en particular O. G. S. Crawford, que trabajó fundamentalmente entre 1931 y 1957 (https:/www. arch.ox.ac.uk/ogs-crawford-archive), o J. K. St. Joseph, quien ya trabajó con fotografías aéreas durante la Segunda Guerra Mundial. Sus trabajos tuvieron mucha influencia a nivel internacional y contribuyeron a sentar las bases de la fotointerpretación arqueológica del siglo XX (Orejas, 1995). En las décadas siguientes se produjeron aportaciones técnicas decisivas, como la contribución de Scollar, ya en los años 1960 y 1970 , desarrollando el análisis informático y la rectificación automatizada de fotografías aéreas. fundamentalmente por herbáceas y matorral. Estas condiciones generan un mayor contraste entre unos suelos pobres, sin potencia y muy pedregosos, y las improntas dejadas por los fosos, haciendo que las trazas de los campamentos sean más perceptibles.

El recurso al análisis secuencial de vuelos de diferentes fechas es un medio eficaz para identificar y analizar formalmente los elementos que componen el paisaje. La comparación de fotografías aéreas obtenidas en distintos momentos del año, permite captar con precisión los cambios en la vegetación que revelan los restos del subsuelo. Los vuelos históricos son, además, una ventana para la detección de estructuras que en la actualidad se encuentran desaparecidas o profundamente transformadas. Este tipo de enfoque se ha mostrado de gran utilidad, por ejemplo, en el análisis de los indicios del posible campamento de Valado, en la zona minera del río Alva (Sánchez-Palencia y Currás, 2015).

Para el estudio del conjunto de evidencias que aquí presentamos se han empleado todos los vuelos disponibles para la zona (Tab. 1). El vuelo Interministerial, el del PNOA de 2011 y el de Google Earth de 2016 son los que muestran las estructuras soterradas con mayor claridad. Sin embargo, no siempre es posible establecer una fotointerpretación completa a partir de un único vuelo, por lo que es necesario emplear de forma combinada las fotografías de diferentes años, con el fin de poder contrastar partes dudosas y descubrir nuevos matices. Las imágenes en falso color infrarrojo son particularmente útiles al efecto.

Las fotografías de los vuelos de la USAF de 1946 y 1956 han sido fundamentales en los estudios del territorio del noroeste peninsular y, de forma específica, han servido para la identificación de diversas estructuras campamentales como las de Valdemeda (Sánchez-Palencia, 1986) o A Chá de Santa Marta (Orejas et alii, 2015). En el caso que nos ocupa, aunque las fotografías se obtienen en un momento en el que toda la superficie de la terraza está en cultivo, la elevada escala del vuelo (1:33.000) y las limitaciones en la definición de la película dificultan la detección de un tipo de estructuras del subsuelo que aparece en forma de unas marcas someras. A pesar de las dificultades para rastrear las trazas de las estructuras castrenses, el llamado vuelo americano ha revelado elementos que no se observaban en fotografías posteriores, permitiendo reconocer componentes estructurales relevantes, como en el caso de R-13. 
Tabla 1. Fotografía aérea analizada.

\begin{tabular}{|c|c|c|}
\hline Vuelo americano USAF & 1946 & \\
\hline Vuelo americano USAF & $27 / 07 / 1956$ & \\
\hline Vuelo interministerial & $(1973-1986)$ & \\
\hline Vuelo nacional (1980-1986) & $28 / 07 / 1984$ & \\
\hline SIGPAC 1997-2003 & & \\
\hline PNOA 2004 & & $45 \mathrm{~cm}$ \\
\hline PNOA 2006 & & $45 \mathrm{~cm}$ \\
\hline PNOA 2008 & & $22 \mathrm{~cm}$ \\
\hline PNOA 2010 & $20 / 08 / 2010$ & $45 \mathrm{~cm}$ \\
\hline PNOA 2011 & $24 / 06 / 2011$ & $45 \mathrm{~cm}$ \\
\hline PNOA 2014 & $27 / 07 / 2014$ & $45 \mathrm{~cm}$ \\
\hline PNOA 2017 & $03 / 07 / 2017$ & $35 \mathrm{~cm}$ \\
\hline Google Earth & $07 / 06 / 2016$ & \\
\hline
\end{tabular}

En el estudio de las marcas del suelo, las estructuras de tipo negativo suelen ser más visibles en el comienzo del verano, momento en el que los campos comienzan a amarillear y cuando se hace más patente sobre el terreno el contraste de las zonas de fosos, más profundas y donde la vegetación tarda más tiempo en marchitar. De los vuelos manejados en el estudio del área de Trobajo/ Oteruelo, aquellos obtenidos entre el final de junio y el principio de julio son los que ofrecen una imagen más nítida de las estructuras militares. Por otro lado, el momento inmediatamente posterior a la siega es igualmente adecuado para observar este tipo de marcas, por un crecimiento más rápido de los cultivos, pero esta es una variable que carece de utilidad para estas tierras, abandonadas desde hace décadas.

El uso combinado de diferentes vuelos también ayuda a un filtrado más eficaz de las trazas observadas sobre el terreno. No todas las marcas que se observan en superficie se corresponden siempre con estructuras del subsuelo, y algunas de las que hoy vemos responden en realidad a elementos recientes. De ahí la importancia de los análisis secuenciales y de integrar la información procedente de diferentes vuelos tomados en distintos momentos del año. Es, además, necesario centrarse en aquellas huellas persistentes en diferentes fotogramas y que además son discordantes respecto al parcelario y al sentido de las marcas de arado de la tierra. Es decir, que se identifican como elementos anómalos respecto a la morfología del paisaje agrario contemporáneo (Orejas, 2011; Currás et alii, 2015). De forma particular, conviene prestar atención a los trazos curvos que se observan en la fotografía que, aunque pueden parecer esquinas de recintos, también pueden corresponder a la vuelta del arado en los extremos de las antiguas parcelas de cultivo.

Por otro lado, los datos LiDAR del PNOA no han arrojado ninguna luz sustancial al análisis formal de las evidencias castrenses. En la topografía con resolución de $1 \mathrm{~m}$ representada con herramientas de visualización del relieve como Hill-shaded, Sky-view factor (Zakšek et alii, 2011) o Local Relief Model (Hesse, 2010) no se aprecian elementos estructurales de ninguno de los recintos, que sí se observan en la fotografía aérea, con la única excepción de R-5, en donde el tratamiento de los datos LiDAR sí muestra tenues indicios del recinto. Esto podría deberse a la completa desaparición de los restos de las estructuras de delimitación tras siglos de aprovechamiento agrícola y de arado continuado de la tierra, o acaso se explica porque sus escasos vestigios no son apreciables con la resolución que aportan los datos del PNOA.

Hay que tener en cuenta además que los datos LiDAR carecen de la profundidad diacrónica que ofrece la fotografía aérea histórica anterior a las grandes transformaciones del medio rural de los años 1960 y 1970. En el conjunto que nos ocupa hay evidencias de estructuras, como las correspondientes a R-14 y R-15, que se encuentran total o parcialmente desaparecidas por el desarrollo urbanístico y que solo se aprecian en la fotografía de los años 1970. El LiDAR es una herramienta plenamente incorporada ya al análisis del territorio, pero debemos ser conscientes de sus limitaciones y de la necesidad de emplear las topografías de alta resolución de forma integrada con el estudio secuencial de la fotografía aérea histórica.

\section{DESCRIPCIÓN DEL CONJUNTO}

El conjunto de recintos campamentales presenta unas características formales marcadamente homogéneas. En todos los casos en los que se ha documentado la totalidad del recinto se trata de estructuras de planta rectangular, con las esquinas redondeadas, que muestran la típica forma de "naipe", característica de los campamentos altoimperiales (Fig. 3). Su configuración es regular, sin variaciones significativas entre los laterales 
Tabla 2. Dimensiones de los recintos. *: estimado por interpolación; SV: sin valor; a: las medidas laterales se toman respecto a su amplitud máxima, tomando como referencia la intersección de la proyección de cada uno de las líneas laterales; b: pendiente expresada en tanto por ciento, calculada sobre un MDE elaborado a partir de los datos LiDAR del PNOA; c: las medidas se toman sobre la máxima extensión del recinto, correspondiente al extremo exterior del segundo foso identificado.

\begin{tabular}{|c|c|c|c|c|c|c|c|c|c|c|}
\hline SIGLA & superficie & $\begin{array}{c}\text { perímetro } \\
\text { documen- } \\
\text { tado }\end{array}$ & $\begin{array}{c}\text { eje } \\
\text { mayor }\end{array}$ & $\begin{array}{c}\text { eje } \\
\text { menor }\end{array}$ & $\begin{array}{c}\text { lateral }^{\mathrm{a}} \\
\mathbf{O}\end{array}$ & $\begin{array}{c}\text { lateral } \\
\mathbf{N}\end{array}$ & $\begin{array}{c}\text { lateral } \\
\mathbf{E}\end{array}$ & $\begin{array}{c}\text { lateral } \\
\mathrm{S}\end{array}$ & $\begin{array}{l}\text { Pendiente } \\
\text { superficie }^{b}\end{array}$ & Módulo \\
\hline R-1 & 1,45 ha & $479 \mathrm{~m}$ & $150 \mathrm{~m}$ & $96,5 \mathrm{~m}$ & $97,2 \mathrm{~m}$ & $150 \mathrm{~m}$ & $95,7 \mathrm{~m}$ & $151,9 \mathrm{~m}$ & $1,2 \%$ & $\begin{array}{l}1,55 \\
(3: 2)\end{array}$ \\
\hline R-2 & 1,06 ha & $404 \mathrm{~m}$ & $125 \mathrm{~m}$ & $85 \mathrm{~m}$ & $125 \mathrm{~m}$ & $84,7 \mathrm{~m}$ & $125 \mathrm{~m}$ & $86 \mathrm{~m}$ & $2,4 \%$ & $\begin{array}{l}1,47 \\
(3: 2)\end{array}$ \\
\hline R-3 & 1,19 ha & $435,7 \mathrm{~m}$ & $133 \mathrm{~m}$ & $90 \mathrm{~m}$ & $91 \mathrm{~m}$ & $132,5 \mathrm{~m}$ & $88,5 \mathrm{~m}$ & $134,5 \mathrm{~m}$ & $1,8 \%$ & $\begin{array}{l}1,48 \\
(3: 2)\end{array}$ \\
\hline R-4 & 0,79 ha & $346,8 \mathrm{~m}$ & $107,7 \mathrm{~m}$ & $74,7 \mathrm{~m}$ & $74,8 \mathrm{~m}$ & $107,3 \mathrm{~m}$ & $74,3 \mathrm{~m}$ & $108,2 \mathrm{~m}$ & $1,9 \%$ & $\begin{array}{l}1,44 \\
(3: 2)\end{array}$ \\
\hline R-5 & 2,06 ha* & $460,6 \mathrm{~m}$ & $166,6 \mathrm{~m}$ & $125 \mathrm{~m}$ & $166,6 \mathrm{~m}$ & $122,6 \mathrm{~m}^{*}$ & $166 \mathrm{~m}$ & $126,3 \mathrm{~m}$ & $1,4 \%$ & $\begin{array}{l}1,33 \\
(4: 3)\end{array}$ \\
\hline $\mathrm{R}-6$ & $S V$ & $312 \mathrm{~m}$ & $S V$ & SV & $S V$ & $S V$ & 184,8 & $S V$ & $S V$ & $S V$ \\
\hline $\mathrm{R}-7$ & $S V$ & $344,6 \mathrm{~m}$ & $S V$ & $113,2 \mathrm{~m}$ & $S V$ & $113,5 \mathrm{~m}$ & $S V$ & $S V$ & $S V$ & $S V$ \\
\hline R-8 & $S V$ & $185,4 \mathrm{~m}$ & $S V$ & $S V$ & $S V$ & $S V$ & $S V$ & $105,5 \mathrm{~m}$ & $S V$ & $S V$ \\
\hline R-9 & 0,53 ha* $^{*}$ & $246,8 \mathrm{~m}$ & $84 \mathrm{~m}$ & $63,5 \mathrm{~m}$ & $63,5 \mathrm{~m}$ & $84 \mathrm{~m}^{*}$ & $63,3 \mathrm{~m}$ & $83,8 \mathrm{~m}$ & $1,3 \%$ & $\begin{array}{l}1,32 \\
(4: 3)\end{array}$ \\
\hline R-10 & $S V$ & $136,5 \mathrm{~m}$ & $S V$ & $S V$ & $S V$ & $S V$ & $102 \mathrm{~m}$ & $S V$ & $S V$ & $S V$ \\
\hline R-11 & $S V$ & $157,8 \mathrm{~m}$ & $S V$ & $S V$ & $S V$ & $S V$ & $S V$ & $S V$ & $S V$ & $S V$ \\
\hline R-12 & $S V$ & $164,3 \mathrm{~m}$ & $S V$ & $92,7 \mathrm{~m}$ & $S V$ & $S V$ & $S V$ & $S V$ & $S V$ & $S V$ \\
\hline R-13 & $S V$ & $435,12 \mathrm{~m}$ & $214 \mathrm{~m}$ & $S V$ & $S V$ & $214 \mathrm{~m}^{*}$ & $S V$ & $S V$ & $S V$ & $S V$ \\
\hline R-14 & $S V$ & $72 \mathrm{~m}$ & $S V$ & $S V$ & $S V$ & $S V$ & $S V$ & $S V$ & $S V$ & $S V$ \\
\hline R-15 & 3,17 ha & $701,04 \mathrm{~m}$ & $204,5 \mathrm{~m}$ & $155,5 \mathrm{~m}$ & $204 \mathrm{~m}$ & $156 \mathrm{~m}$ & $204,2 \mathrm{~m}$ & $155,3 \mathrm{~m}$ & $S V$ & $\begin{array}{l}1,31 \\
(4: 3)\end{array}$ \\
\hline R-16 & 0,4 ha & $249 \mathrm{~m}$ & $73,7 \mathrm{~m}$ & $55,3 \mathrm{~m}$ & $73,5 \mathrm{~m}$ & $55,2 \mathrm{~m}$ & $74 \mathrm{~m}$ & $55,5 \mathrm{~m}$ & $3,1 \%$ & $\begin{array}{l}1,33 \\
(4: 3)\end{array}$ \\
\hline R-17 & 0,51 ha & $282,2 \mathrm{~m}$ & $72 \mathrm{~m}$ & $71 \mathrm{~m}$ & $72,7 \mathrm{~m}$ & $70,5 \mathrm{~m}$ & $71,3 \mathrm{~m}$ & $71,3 \mathrm{~m}$ & $1,9 \%$ & $\begin{array}{l}1,01 \\
(1: 1)\end{array}$ \\
\hline R-18c & 0,5 ha* & $180 \mathrm{~m}$ & $79 \mathrm{~m}$ & $67 \mathrm{~m}$ & $80 \mathrm{~m}$ & $64 \mathrm{~m}$ & $77 \mathrm{~m}^{*}$ & $68 \mathrm{~m}^{*}$ & $S V$ & 1,15 \\
\hline
\end{tabular}

opuestos. El tamaño es muy variable, dentro de un rango que oscila entre las 3 y 0,5 ha. Sin embargo, responden con gran precisión a dos únicos módulos de $3: 2$ y 4:3, que corresponden a una planta rectangular más o menos estilizada (Tabs. 2 y 3). Dentro del conjunto, tan solo desentonan $\mathrm{R}-17$, con una planimetría cuadrada y un módulo 1:1 y R-18. La superficie interior de todos los recintos está perfectamente nivelada, con una pendiente media del $2 \%$ comprendida en un rango de 1-3\%. Esto es coherente con la propia topografía natural del terreno, una plataforma marcadamen- te llana, en la que no fue necesaria ninguna obra de infraestructura o acondicionamiento previo del terreno. En ningún caso se han podido observar interrupciones claras en el trazado del perímetro, que pudieran significar accesos a los recintos. Ni siquiera se verifican entradas en aquellos que presentan su planta íntegra y que aparecen de forma más nítida en la fotografía aérea. Tan solo en el lateral norte de R-18 se aprecian los vestigios de una posible entrada, aunque el hecho de que coincida con una pista reciente invita a tomar los indicios con cautela. 


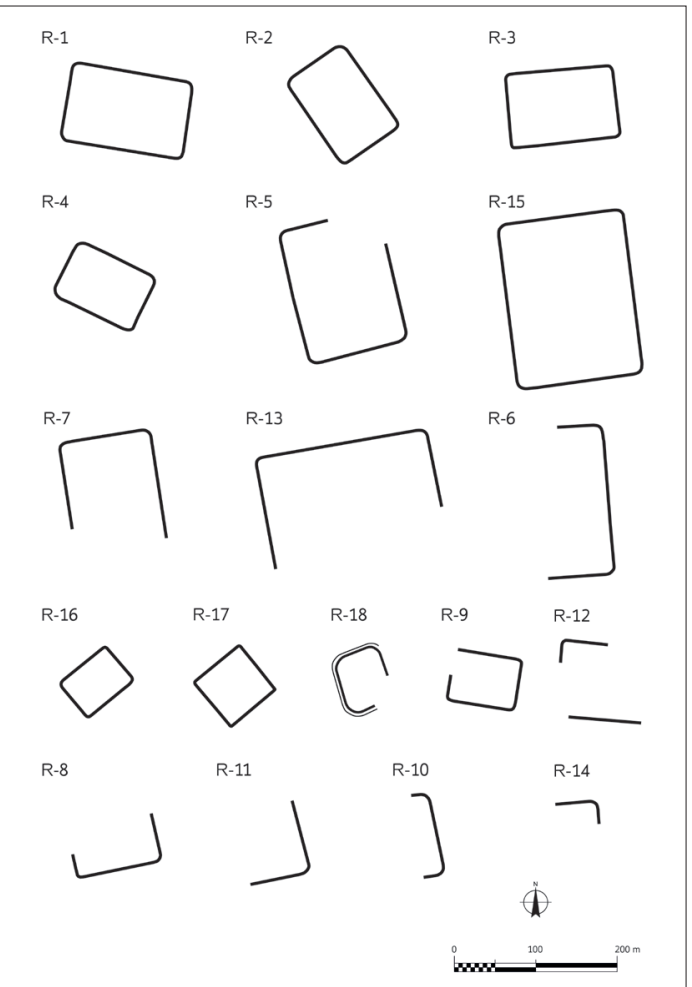

Figura 3. Planta de los recintos identificados en Trobajo del Camino (San Andrés de Rabanedo) y Oteruelo de la Valdoncina (León).

Las evidencias se limitan a la constatación de las fossae que se observan en forma de improntas en la fotografía aérea. No se ha podido observar el terraplén o agger, marcado sin duda por la línea clara contigua a los alineamientos oscuros de la fosa en el terreno. En todos los casos existe un único foso, excepto en R-18 en donde se documenta con claridad la existencia de un foso doble. Probablemente los terraplenes están muy alterados y han sido desmantelados casi por completo por las labores agrícolas. Tan solo en el caso de R-5, observamos las evidencias de un posible agger en la topografía de alta resolución obtenida con datos LiDAR.

De los 18 recintos identificados, 7 aparecen completos, en 3 casos se puede restituir toda su extensión a partir de los segmentos y los 8 restantes son trazados parciales, con uno o dos esquinales. El carácter incompleto de varios de los recintos podría deberse a una conservación deficiente de las estructuras causada, entre otros posibles motivos, por el uso agrícola de la tierra. Igualmente, es posible que parte de las estructuras del subsuelo no se observen en los vuelos analizados y que el carácter parcial de las evidencias documentadas sea solo aparente. Cabe por último la posibilidad de que estemos en realidad ante recintos inconclusos, que respondan a la realización de prácticas centradas solo en partes de los perímetros.

Los datos que se incluyen en la descripción de cada uno de los recintos y en la correspondiente tabla responden a cálculos efectuados a partir de los trazados identificados, tal y como se ha expuesto más arriba. Como se verá a continuación, hay claras evidencias de modulaciones, con relaciones $3: 2$, 4:3 y 1:1. No obstante, estas mediciones podrán ser matizadas y precisadas, gracias a trabajos en curso.

\section{R-1}

El recinto R-1 es uno de los mejor conservados de todo el conjunto (Fig. 4). Su estructura, conservada íntegra, se puede apreciar en prácticamente todos los vuelos consultados. Se acomoda a la perfección a un módulo de 3:2.

\section{R-2}

El trazado del perímetro presenta algunas alteraciones causadas por los caminos modernos, así como por las construcciones de una finca que afecta sobre todo a su zona meridional, pero su estructura puede ser reconstruida a partir del uso combinado de varios vuelos (Fig. 5). Este recinto se ajusta con gran precisión a un módulo de 3:2.

\section{R-3}

Conserva su estructura completa, aunque aparece bastante difuminada en la mayor parte de los vuelos (Fig. 6). La entidad del esquinal SO es bastante dudosa y, aunque se intuye en la fotografía aérea del vuelo del PNOA de 2011, es posible que esa parte del recinto quedase inconclusa. En todo caso, a partir de los elementos conservados se puede completar su planta, que corresponde a un módulo de 3:2.

\section{R-4}

Es, junto a R-1, la estructura mejor conservada y se puede observar en la mayor parte de los vuelos (Fig. 7). Tiene un eje mayor de exactamente 3 actus por 2,1 en el eje menor. Su proporción revela un módulo de 3:2. 
Tabla 3. Dimensiones de los recintos en medidas romanas. *: estimado por interpolación; actus: 35,439 m; pes: $0,2957 \mathrm{~m}$; actus quadratus: $1259 \mathrm{~m}^{2}$.

\begin{tabular}{|c|c|c|c|c|c|c|c|c|c|}
\hline SIGLA & $\begin{array}{l}\text { Superficie } \\
\text { actus } \\
\text { quadratus }\end{array}$ & & \begin{tabular}{|c|}
$\begin{array}{c}\text { Perímetro } \\
\text { documen- } \\
\text { tado }\end{array}$ \\
\end{tabular} & eje mayor & eje menor & $\begin{array}{l}\text { lateral } \\
\mathbf{0}\end{array}$ & $\begin{array}{c}\text { lateral } \\
\mathbf{N}\end{array}$ & $\begin{array}{c}\text { lateral } \\
\mathbf{E}\end{array}$ & $\begin{array}{l}\text { lateral } \\
\mathrm{S}\end{array}$ \\
\hline \multirow{2}{*}{ R-1 } & \multirow{2}{*}{11,5} & pedes & $1.619,9$ & 507,3 & 326,3 & 328,7 & 507,3 & 323,6 & 513,7 \\
\hline & & actus & 13,5 & 4,2 & 2,7 & 2,7 & 4,2 & 2,7 & 4,3 \\
\hline \multirow{2}{*}{$\mathrm{R}-2$} & \multirow{2}{*}{8,4} & pedes & $1.366,2$ & 422,7 & 287,5 & 422,7 & 286,4 & 422,7 & 290,8 \\
\hline & & actus & 11,4 & 3,5 & 2,4 & 3,5 & 2,4 & 3,5 & 2,4 \\
\hline \multirow{2}{*}{$\mathrm{R}-3$} & \multirow{2}{*}{9,5} & pedes & $1.473,5$ & 449,8 & 304,4 & 307,7 & 448,1 & 299,3 & 454,9 \\
\hline & & actus & 12,3 & 3,8 & 2,5 & 2,6 & 3,7 & 2,5 & 3,8 \\
\hline \multirow{2}{*}{$\mathrm{R}-4$} & \multirow{2}{*}{6,3} & pedes & $1.172,8$ & 364,2 & 252,6 & 253,0 & 362,9 & 251,3 & 365,9 \\
\hline & & actus & 9,8 & 3,0 & 2,1 & 2,1 & 3,0 & 2,1 & 3,1 \\
\hline \multirow{2}{*}{ R-5 } & \multirow{2}{*}{$16,4^{*}$} & pedes & $1.557,7$ & 563,4 & 422,7 & 563,4 & $414,6^{*}$ & 561,4 & 427,1 \\
\hline & & actus & 13,0 & 4,7 & 3,5 & 4,7 & $3,5^{*}$ & 4,7 & 3,6 \\
\hline \multirow{2}{*}{$\mathrm{R}-6$} & \multirow{2}{*}{ SV } & pedes & $1.055,1$ & SV & $\mathrm{SV}$ & SV & SV & 625,0 & SV \\
\hline & & actus & 8,8 & SV & $\mathrm{SV}$ & SV & SV & 5,2 & SV \\
\hline \multirow{2}{*}{$\mathrm{R}-7$} & \multirow{2}{*}{ SV } & pedes & $1.165,4$ & SV & 382,8 & SV & 383,8 & SV & SV \\
\hline & & actus & 9,7 & SV & 3,2 & SV & 3,2 & SV & $\mathrm{SV}$ \\
\hline \multirow{2}{*}{$\mathrm{R}-8$} & \multirow{2}{*}{ SV } & pedes & 627,0 & SV & SV & SV & SV & $\mathrm{SV}$ & 356,8 \\
\hline & & actus & 5,2 & SV & $\mathrm{SV}$ & SV & SV & SV & 3,0 \\
\hline \multirow{2}{*}{ R-9 } & \multirow{2}{*}{$4,2^{*}$} & pedes & 834,6 & 284,1 & 214,7 & 214,7 & $284,1 *$ & 214,1 & 283,4 \\
\hline & & actus & 7,0 & 2,4 & 1,8 & 1,8 & $2,4^{*}$ & 1,8 & 2,4 \\
\hline \multirow{2}{*}{ R-10 } & \multirow{2}{*}{ SV } & pedes & 461,6 & SV & SV & SV & SV & 344,9 & $\mathrm{SV}$ \\
\hline & & actus & 3,9 & SV & SV & SV & SV & 2,9 & $\mathrm{SV}$ \\
\hline \multirow{2}{*}{$\mathrm{R}-11$} & \multirow{2}{*}{ SV } & pedes & 533,6 & SV & SV & SV & SV & SV & SV \\
\hline & & actus & 4,5 & SV & $\mathrm{SV}$ & SV & SV & SV & $\mathrm{SV}$ \\
\hline \multirow{2}{*}{$\mathrm{R}-12$} & \multirow{2}{*}{ SV } & pedes & 555,6 & SV & 313,5 & SV & SV & $\mathrm{SV}$ & $\mathrm{SV}$ \\
\hline & & actus & 4,6 & $\mathrm{SV}$ & 2,6 & SV & SV & SV & SV \\
\hline \multirow{2}{*}{$\mathrm{R}-13$} & \multirow{2}{*}{ SV } & pedes & $1.471,5$ & 723,7 & $\mathrm{SV}$ & SV & $723,7 *$ & SV & $\mathrm{SV}$ \\
\hline & & actus & 12,3 & 6,0 & SV & SV & $6,0^{*}$ & SV & SV \\
\hline R_-14 & SV & pedes & 243,5 & SV & $\mathrm{SV}$ & SV & SV & $\mathrm{SV}$ & SV \\
\hline K-14 & $S V$ & actus & 2,0 & $\mathrm{SV}$ & $\mathrm{SV}$ & SV & SV & $\mathrm{SV}$ & $\mathrm{SV}$ \\
\hline$P_{-15}$ & 252 & pedes & $2.370,8$ & 691,6 & 525,9 & 689,9 & 527,6 & 690,6 & 525,2 \\
\hline $\mathrm{K}-\mathrm{IS}$ & 25,2 & actus & 19,8 & 5,8 & 4,4 & 5,8 & 4,4 & 5,8 & 4,4 \\
\hline D 16 & 22 & pedes & 842,1 & 249,2 & 187,0 & 248,6 & 186,7 & 250,3 & 187,7 \\
\hline$K-10$ & 3,2 & actus & 7,0 & 2,1 & 1,6 & 2,1 & 1,6 & 2,1 & 1,6 \\
\hline D 17 & 1 & pedes & 954,3 & 243,5 & 240,1 & 245,9 & 238,4 & 241,1 & 241,1 \\
\hline $\mathrm{K}-1 /$ & 4,1 & actus & 8,0 & 2,0 & 2,0 & 2,1 & 2,0 & 2,0 & 2,0 \\
\hline P 18 & $4 *$ & pedes & 608,7 & 267,2 & 226,6 & 270,5 & 216,4 & $260,4 *$ & $230,0^{*}$ \\
\hline$k-18$ & 4 & actus & 5,1 & 2,2 & 1,9 & 2,3 & 1,8 & $2,2 *$ & $1,9 *$ \\
\hline
\end{tabular}

\section{R-5}

La estructura R-5 muestra casi todo su perímetro, con la excepción de la esquina NE, que no ha podido ser identificada en ninguna de las fotografías (Fig. 8). Es el único de todos los recintos que ha quedado fosilizando en el parcelario, como se observa sobre todo en el vuelo interministerial de los años 1970 y que además revela su estructura en la topografía obtenida con datos LiDAR. Todo apunta a que es posible que en este recinto se conserve parcialmente el agger.

El perímetro identificado es de 460,6 m, que equivalen exactamente a 13 actus. La restitución del esquinal norte conforme a un plano regular daría un valor de $562,6 \mathrm{~m}$, que se corresponde con 15,9 actus. El valor entero en actus del perímetro documentado sugiere una decisión deli- 


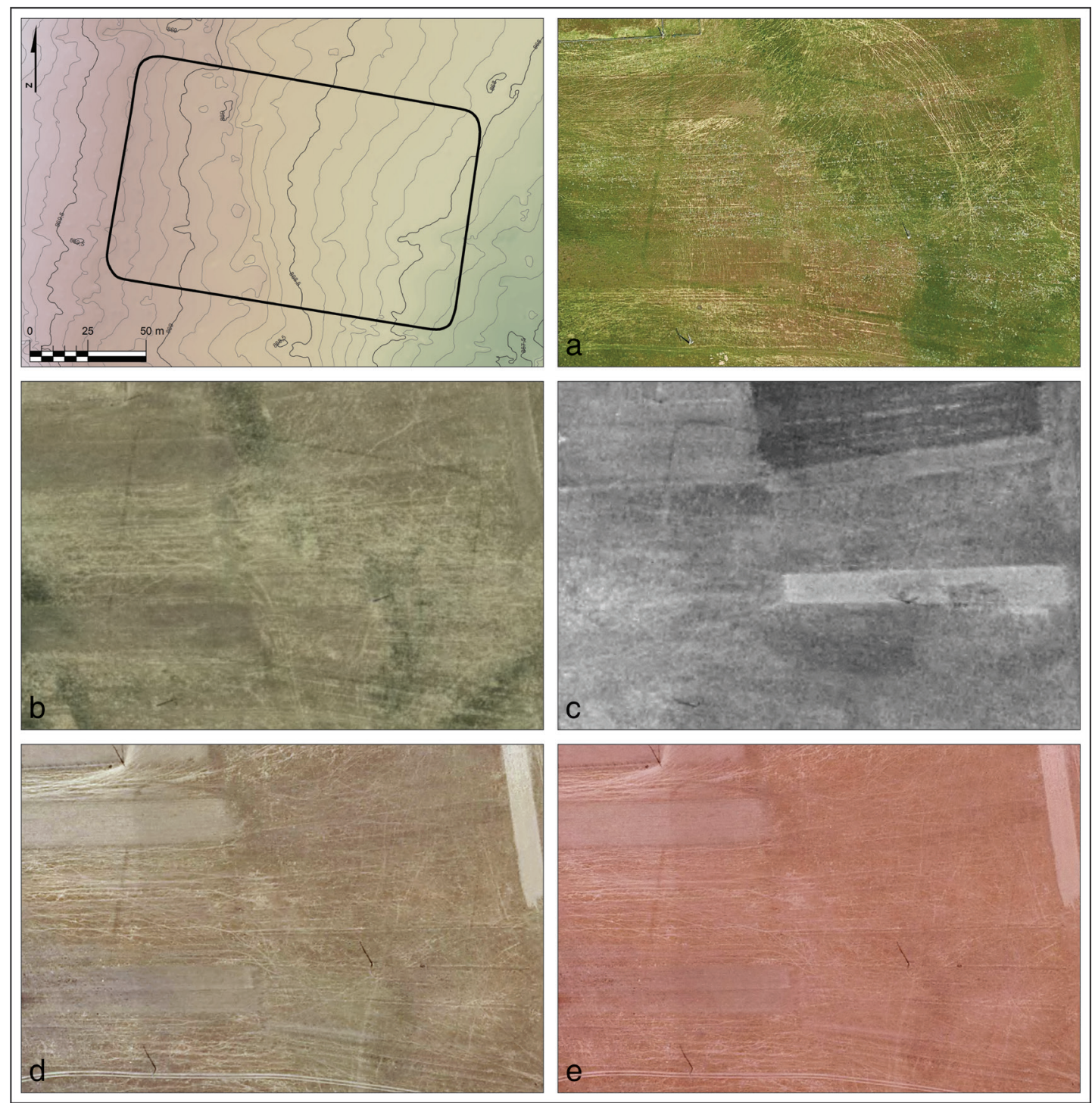

Figura 4. Recinto 1. Curvas de nivel cada $10 \mathrm{~cm}$. a) Google Earth 2016; b) PNOA 2011; c) Interministerial 1973 1986; d) PNOA 2008; e) PNOA 2008 falso color infrarrojo.

berada, que quizás podría ser interpretada como la elección de una longitud determinada y el posterior abandono de la construcción dejando el recinto inconcluso.

Las medidas de los ejes revelan con claridad un módulo perfecto de 4:3.

\section{R-6}

La estructura R-6 se ha identificado parcialmente $\mathrm{y}$ tan solo es visible uno de sus laterales, probablemente correspondiente al eje mayor (Fig. 9). La parte documentada del recinto termina justo en el camino, en el mismo punto en que termina la terraza y se produce un cambio en la pendiente que empieza a evolucionar hacia la plataforma de la terraza superior.

La interpretación del esquinal septentrional es poco clara. En primer lugar, se observa un ángulo que coincide con el trazado de los dos laterales documentados. Pero se puede apreciar también un segundo trazado de una esquina redondeada, que coincide con el lateral septentrional, pero no con el oriental. No queda lo suficientemente claro si esa marca corresponde a una rectificación en el proceso de construcción del recinto, o si, por el 
contrario, no tiene que ver con las estructuras antiguas. Tampoco es descartable que tenga que ver con el procedimiento topográfico para trazar las esquinas redondeadas (coxae).

\section{R-7}

El recinto R-7 diverge en su emplazamiento respecto al resto del conjunto, localizándose en una posición claramente excéntrica (Fig. 10). Se sitúa en la plataforma de la terraza inmediatamente superior a la de los demás recintos, a una cota 15 m más elevada. La mitad meridional no se ha podido observar con suficiente definición en nin- guna de las fotografías analizadas. En la actualidad esa zona se encuentra muy alterada por varias construcciones.

\section{R-8}

Se ha podido documentar únicamente la mitad meridional del recinto, mientras que la parte septentrional aparece ya alterada en el vuelo de los años 1970 (Fig. 11). Existen varios indicios de la esquina NE, pero la existencia de diferentes marcas no permite determinar con suficiente fiabilidad su entidad. Al igual que en R-6, es posible que estas
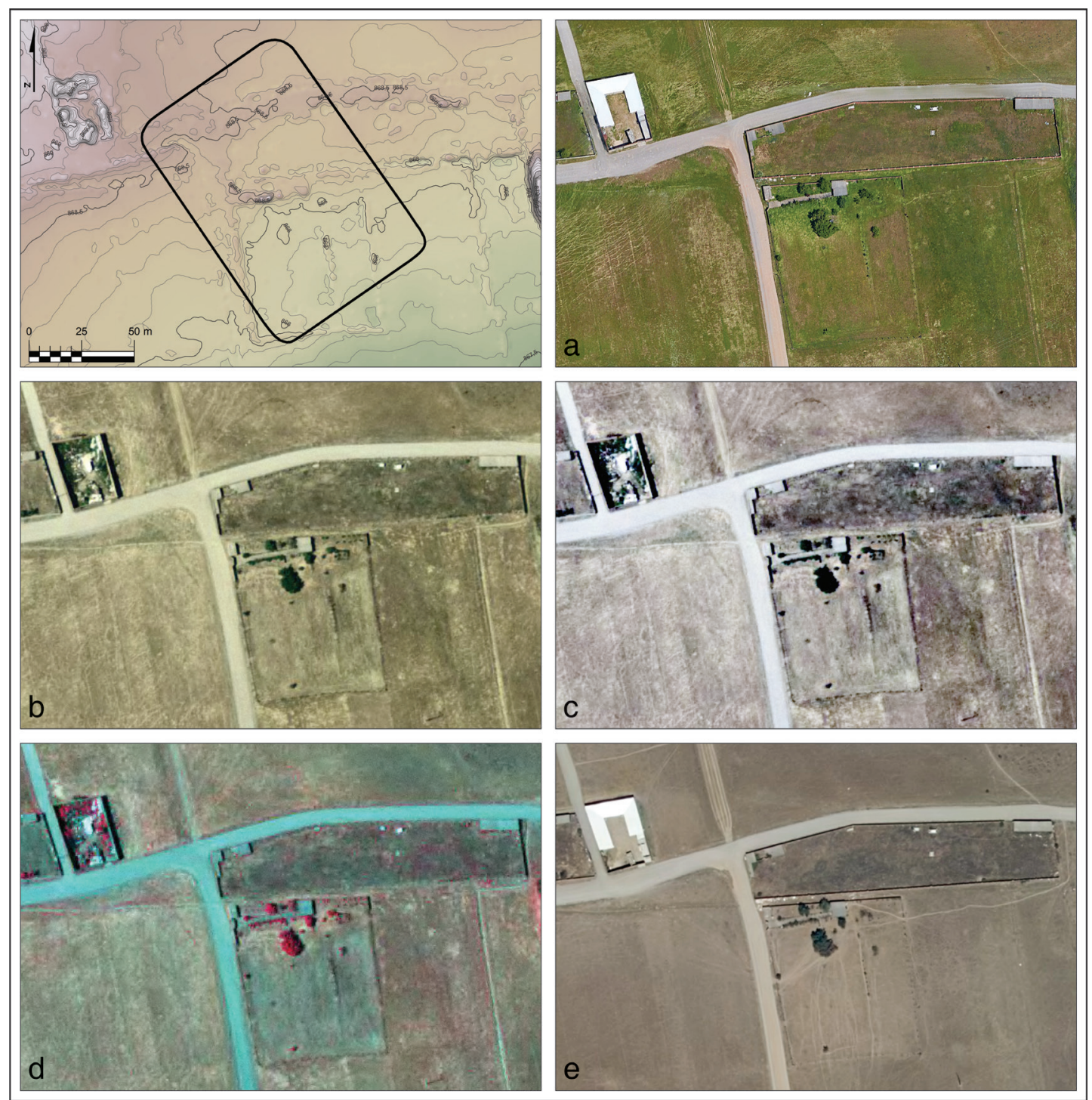

Figura 5. Recinto 2. Curvas de nivel cada $10 \mathrm{~cm}$. a) Google Earth 2016; b) PNOA 2011; c) PNOA 2011 reclasificado; d) PNOA 2011 falso color infrarrojo; e) PNOA 2017. 


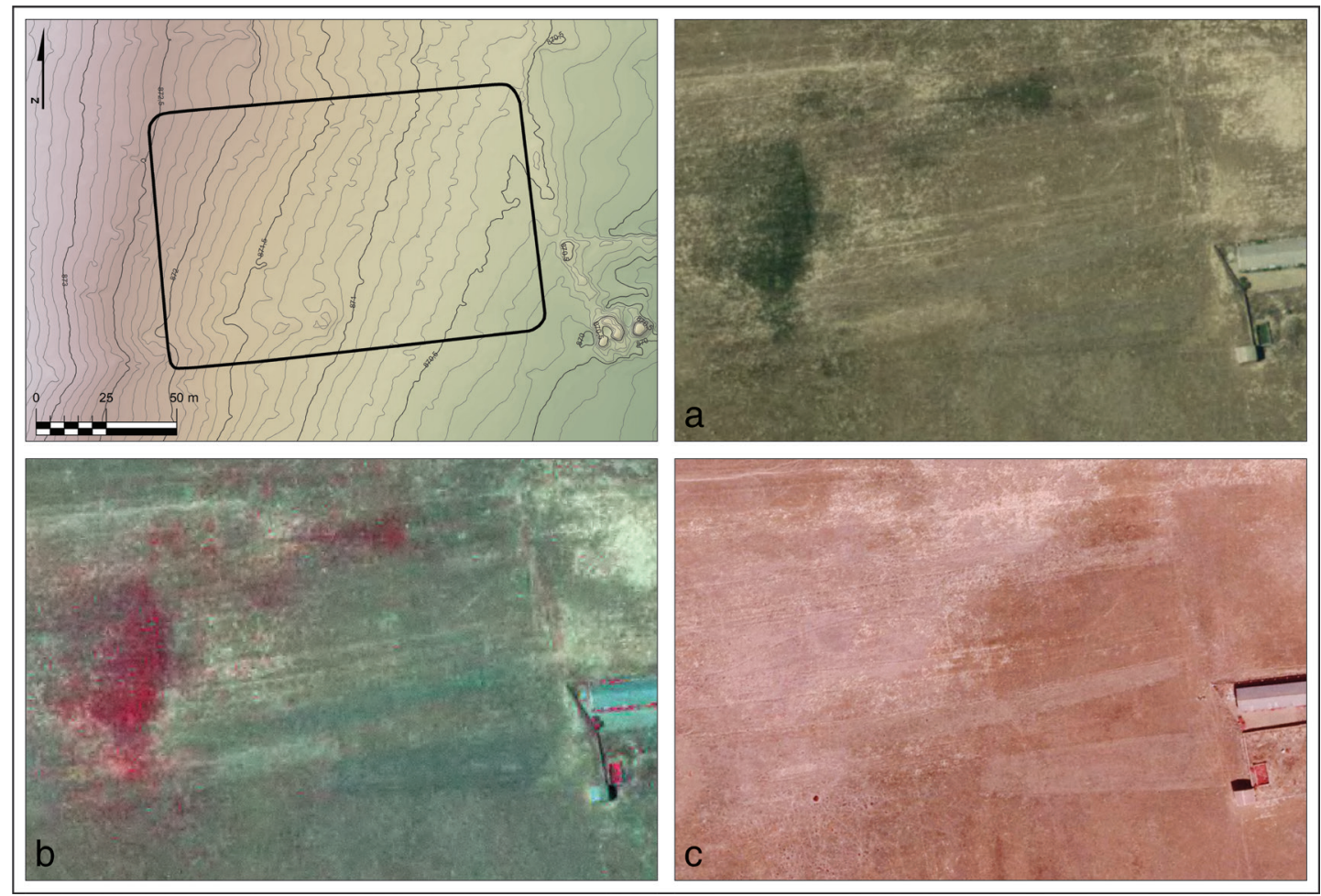

Figura 6. Recinto 3. Curvas de nivel cada $10 \mathrm{~cm}$. a) PNOA 2011; b) PNOA 2011 falso color infrarrojo; c) PNOA 2008 falso color infrarrojo.

marcas correspondan a rectificaciones en el planteamiento del esquinal. Si tomamos el trazado más probable y que se aprecia con mayor claridad en la fotografía, los ejes del campamento serían de 105,7 por $71 \mathrm{~m}$, es decir 3 por 2 actus y un módulo perfecto de 3:2, que es coherente con el resto del conjunto. La superficie ocuparía 6 actus quadratus.

\section{R-9}

El recinto R-9 se ha documentado prácticamente íntegro, con la excepción de la parte afectada por el camino, correspondiente a la parte del lateral $\mathrm{O}$, así como al ángulo $\mathrm{NO}$, que no se han podido observar en ninguna de las fotografías analizadas (Fig. 12). A partir de la medida de los ejes del recinto se obtiene un módulo prácticamente perfecto de 4:3.

El perímetro de la parte identificada alcanza los 246,8 m (7 actus), que darían un total de 285,5 $\mathrm{m}$ si restituimos el esquinal conforme a una planta regular, que serían equivalentes a 8 actus. La superficie total sería de 4,2 actus quadratus.
$\mathrm{Al}$ igual que en $\mathrm{R}-5$, el valor entero de la parte conservada podría estar indicando que la construcción del recinto se detuvo en ese momento de forma intencional.

En todas las fotografías, desde al menos el vuelo interministerial de los años 1970 , se observa una marca lineal sobre el terreno que atraviesa el reciento por su parte SE y que discurre paralela al actual camino. El hecho de que esta estructura resulte perfectamente paralela al vial, indica que quizás se trate de alguna infraestructura de servicio soterrada, pero su entidad y naturaleza no están lo suficientemente claras y no es descartable que se trate de algún elemento antiguo.

\section{R-10}

Se documenta tan solo uno de los laterales del recinto, del que no se puede determinar si corresponde al eje mayor o menor (Fig. 13). En los vuelos de 1946 y 1956 no se aprecian las marcas y en el vuelo interministerial toda la parte occidental, hacia la que continuaría el recinto, está ya arrasada por una construcción. Este recinto intersecta con el trazado de R-11. 


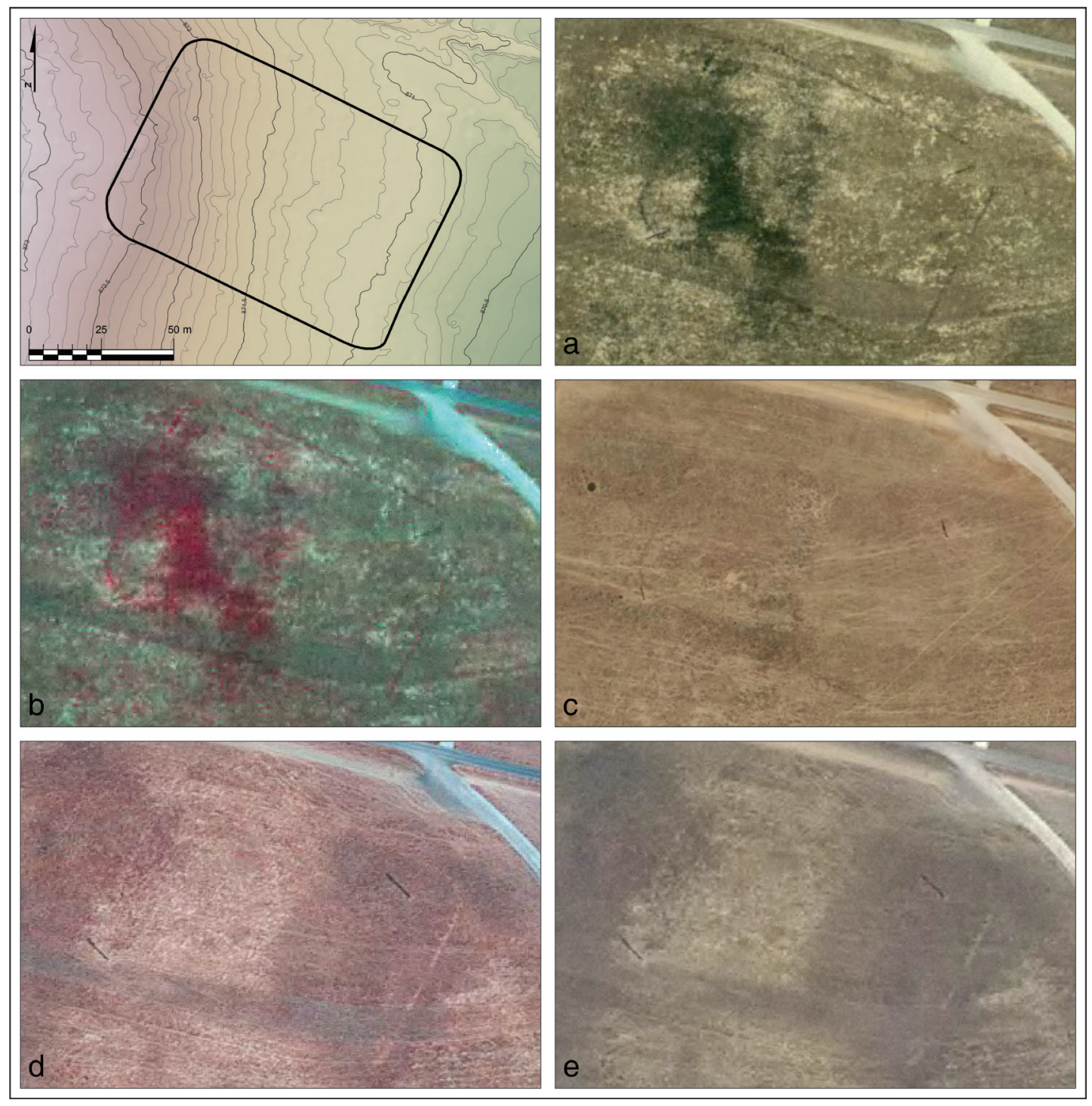

Figura 7. Recinto 4. Curvas de nivel cada $10 \mathrm{~cm}$. a) PNOA 2011; b) PNOA 2011 falso color infrarrojo; c) PNOA 2017; d) PNOA 2010 falso color infrarrojo; e) PNOA 2010.

\section{R-11}

Al igual que R-10, se identifica tan solo parcialmente debido a las alteraciones causadas por un edificio presente ya en la fotografía aérea de los años 1970 (Fig. 13). Se observa tan solo el cuarto suroriental del recinto, que intersecta con R-10 y R-12.

\section{R-12}

El recinto R-12 se encuentra muy alterado por varias construcciones, caminos y por el paso de la carretera (Fig. 13). Se ha podido observar el lateral meridional y el esquinal noroccidental. $\mathrm{Su}$ trazado intersecta con R-11.

\section{R-13}

Se documenta buena parte del recinto, con la excepción de todo el lateral meridional, que no se aprecia en ninguna de las fotografías consultadas, tampoco en el vuelo americano cuando el entorno se encontraba menos modificado (Fig. 14). El eje E-O del recinto, el único que permite obtener una 

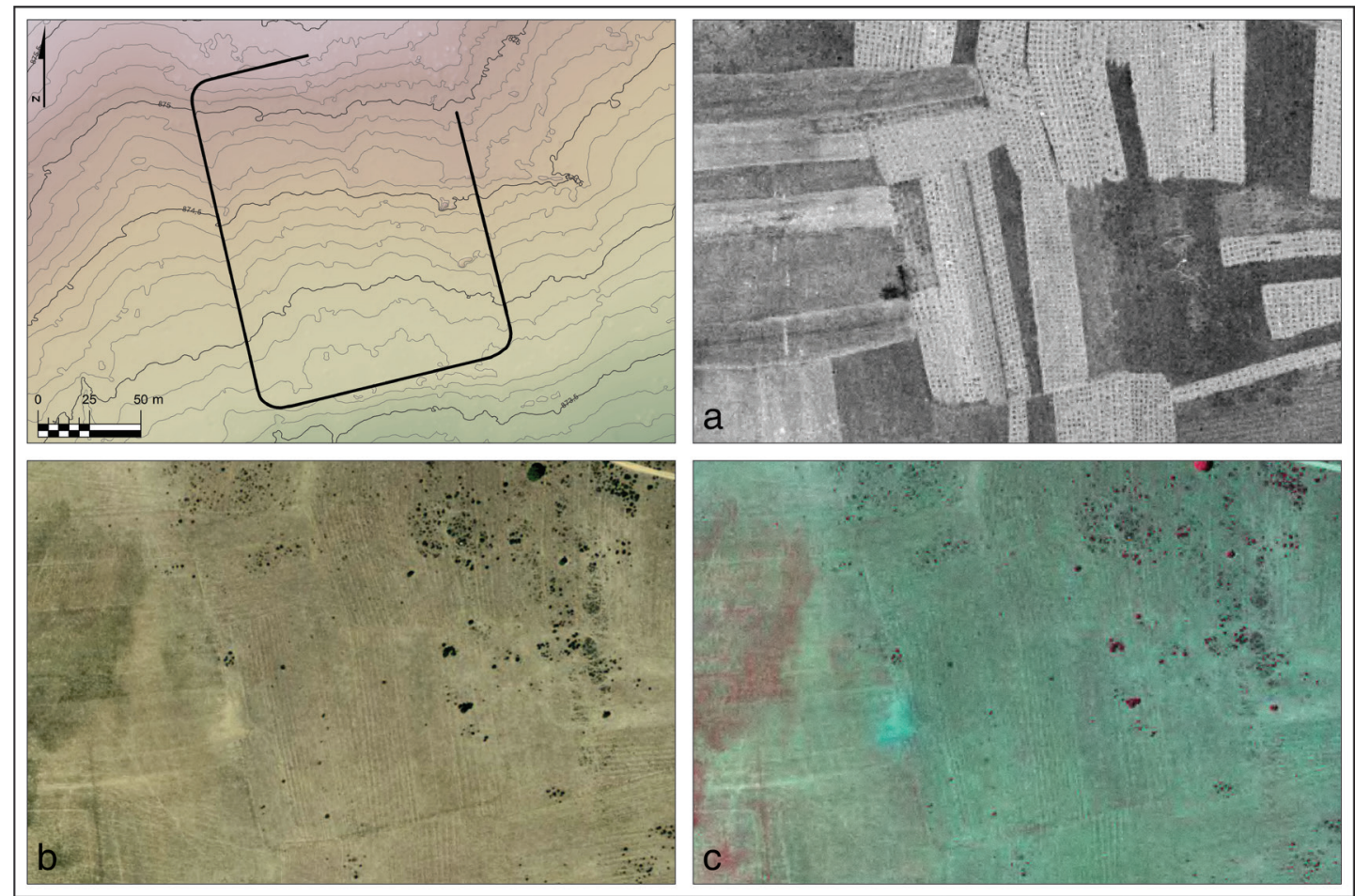

Figura 8. Recinto 5. Curvas de nivel cada $10 \mathrm{~cm}$. a) Interministerial 1973-1986; b) PNOA 2011 falso color infrarrojo; c) PNOA 2011.
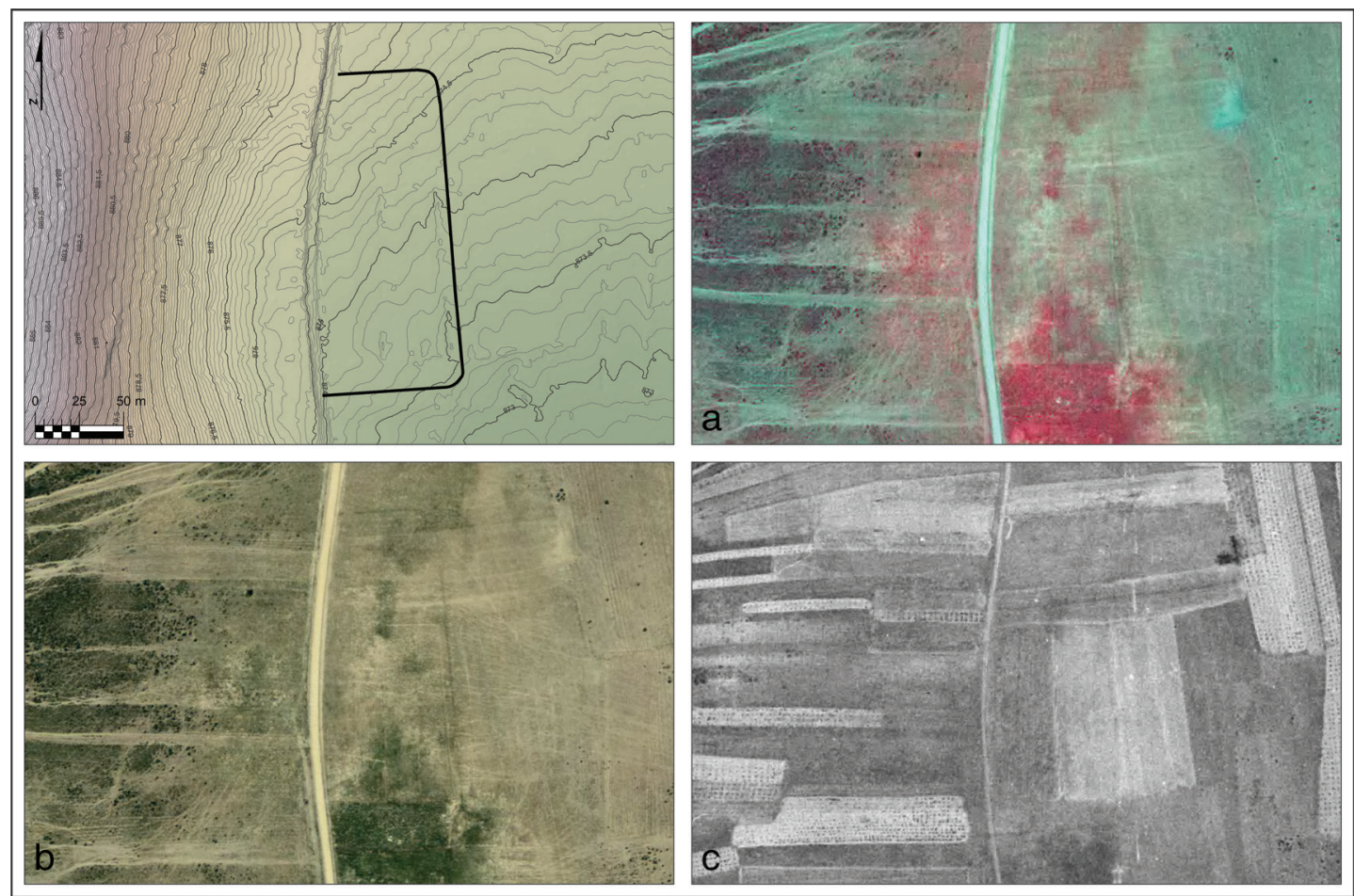

Figura 9. Recinto 6. Curvas de nivel cada $10 \mathrm{~cm}$. a) PNOA 2011 falso color infrarrojo; b) PNOA 2011; c) Interministerial 1973-1986. 
medida significativa ofrece un valor exacto de 6 actus. En la actualidad, toda la zona presenta importantes alteraciones causadas por diversas construcciones y por el paso de la carretera.

En la fotografía se observa una franja que discurre en sentido SO-NE y que lo atraviesa por su zona oriental. Se corresponde con el canal de Velilla, construido entre los años 1960 y 1970 para el regadío. En la fotografía del vuelo interministerial se puede observar en su fase de construcción o en un momento inmediatamente posterior. En las fotografías más recientes aparece como una im- pronta longitudinal, que no difiere en sus características de las marcas dejadas por las fossae.

\section{R-14}

Se documenta únicamente el ángulo NE del recinto en el vuelo interministerial, con una extensión exacta de 2 actus (Fig. 15). La probable vía romana que comunicaba Legio con Asturica Augusta discurre sobre el lateral $\mathrm{N}$ del recinto, a escasos $5 \mathrm{~m}$.
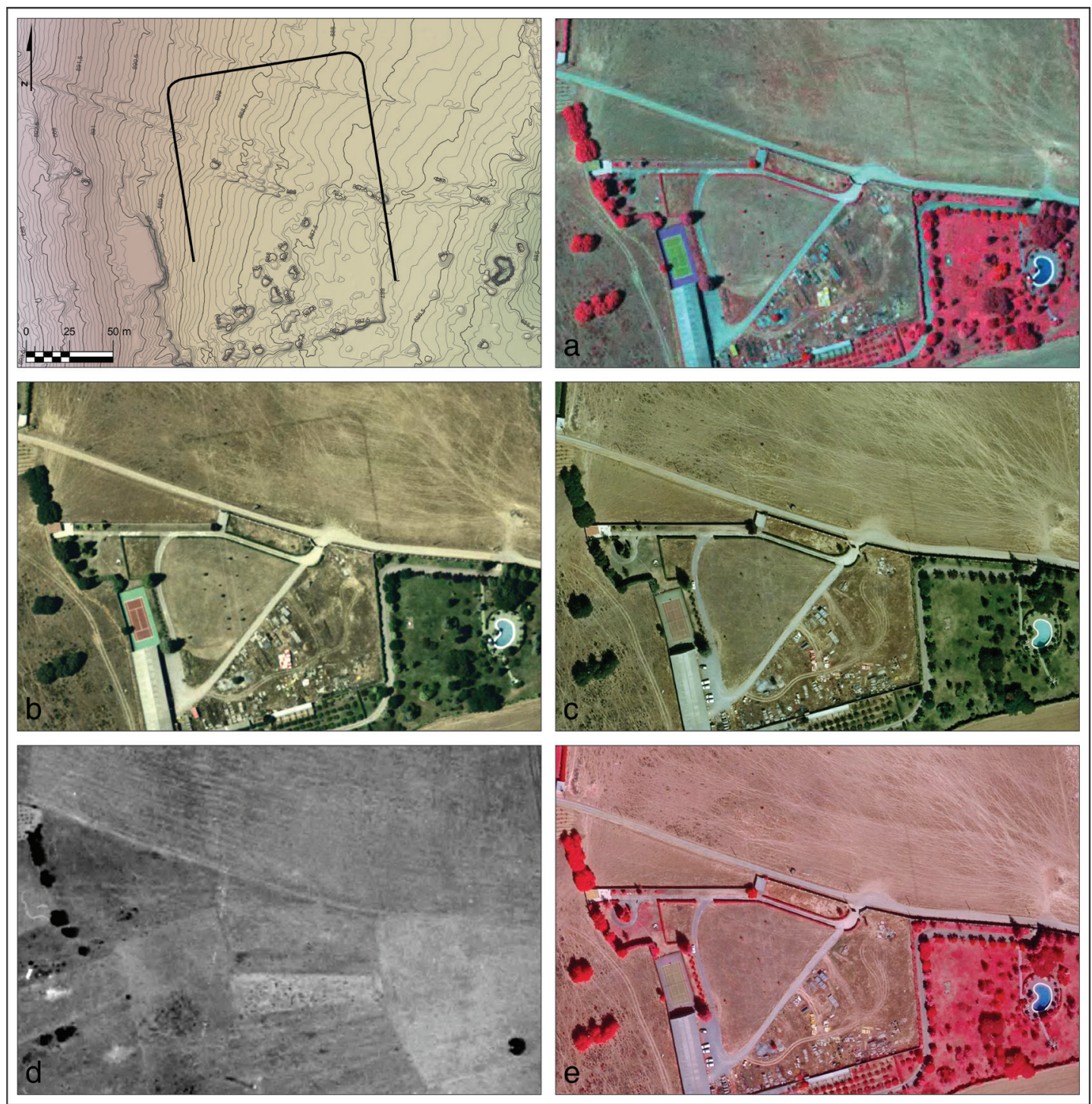

Figura 10. Recinto 7. Curvas de nivel cada $10 \mathrm{~cm}$. a) PNOA 2011 falso color infrarrojo; b) PNOA 2011; c) PNOA 2008; d) Interministerial 1973-1986; e) PNOA 2008 falso color infrarrojo. 


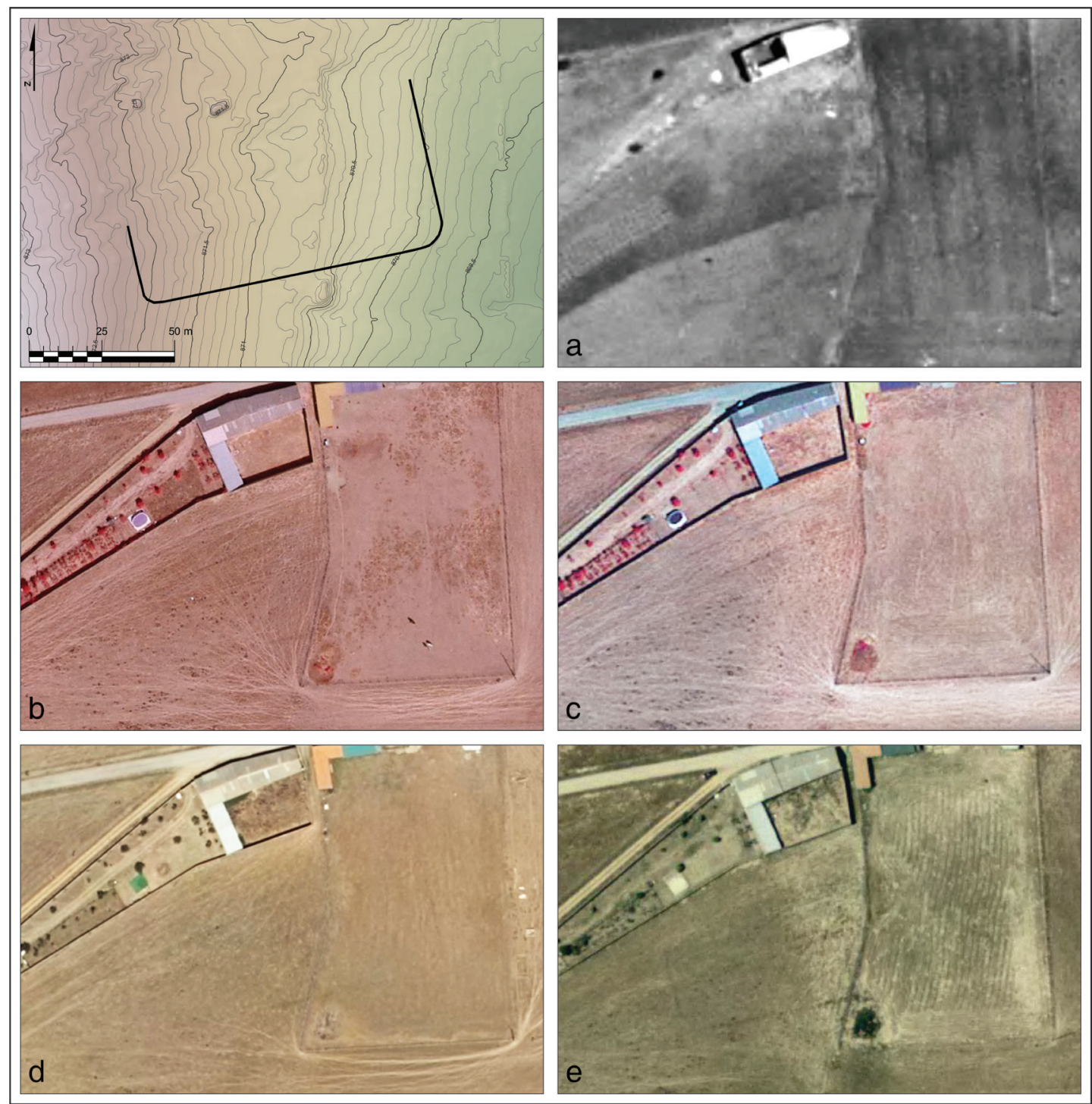

Figura 11. Recinto 8. Curvas de nivel cada $10 \mathrm{~cm}$. a) Interministerial 1973-1986; b) PNOA 2008 falso color infrarrojo; c) PNOA 2010 falso color infrarrojo; d) PNOA 2017; e) PNOA 2011.

En la actualidad el sitio donde se observan las estructuras se encuentra bajo una construcción.

\section{R-15}

El recinto $\mathrm{R}-15$, aunque muy alterado en la actualidad por la construcción de varias naves industriales, se puede identificar en toda su extensión en el vuelo interministerial de los años 1970 (Fig. 15). Se encuentra separado por poco más de
$10 \mathrm{~m}$ de la esquina de $\mathrm{R}-14$, recinto con el que comparte orientación y aparentemente una marcada semejanza estructural. Al igual que R-14, se dispone de forma perfectamente paralela al paso de la vía romana, que discurre a poco menos de 5 m. A pesar de la destrucción de las estructuras antiguas en la fotografía reciente todavía se observa el lateral E, y parte de los laterales S y O.

El perímetro del recinto mide 19,8 actus y su superficie es de 25,2 actus quadratus. Se acomoda con gran exactitud a un módulo de 4:3. 


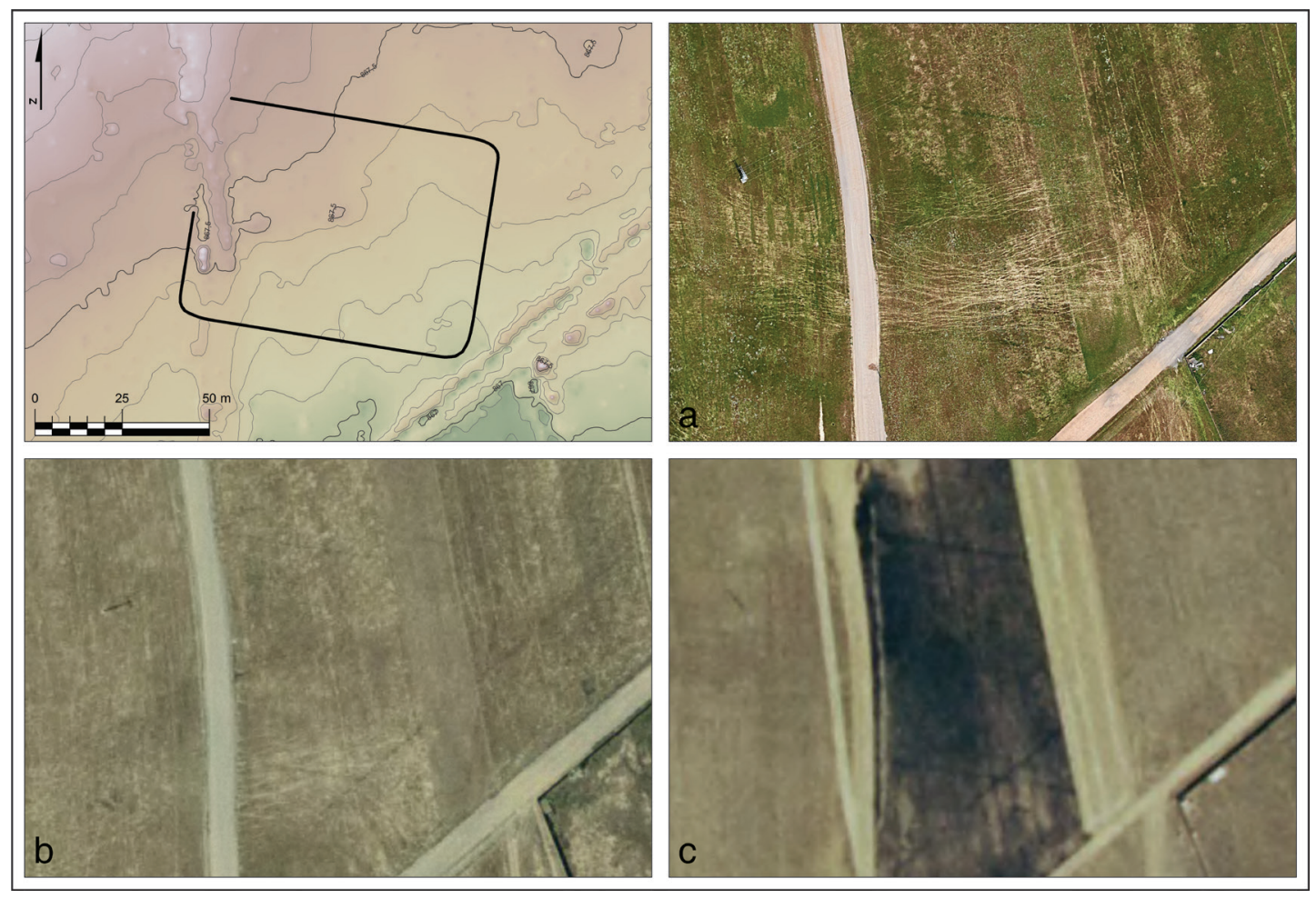

Figura 12. Recinto 9. Curvas de nivel cada 10 cm. a) Google Earth 2016; b) PNOA 2011; c) SIGPAC 1997-2003.

\section{R-16}

Conserva su estructura perfectamente definida en el vuelo interministerial de los años 1970, aunque en los vuelos posteriores no se consigue identificar ninguno de sus componentes estructurales (Fig. 16). Su perímetro mide exactamente 7 actus. Sus proporciones se ajustan con total exactitud a un módulo de 4:3.

\section{R-17}

Se trata del único recinto del conjunto de planta cuadrada (Fig. 17). La medida de los laterales es de 2 actus, lo que da como resultado un perímetro de 8 actus y una superficie total de 4 actus quadratus. Se aprecia en el vuelo americano y el vuelo interministerial, pero ya no se documenta en la fotografía aérea posterior. El recinto se dispone sobre un pequeño espolón que forma el borde de la terraza sobre la vaguada del arroyo de Las Fontanillas, adaptándose al mismo.

\section{R-18}

El recinto R-18 ${ }^{5}$ se sitúa en una posición ligeramente desplazada respecto a la zona donde se concentra la mayor parte de las estructuras, pero dentro de la misma plataforma definida por la terraza intermedia de la margen derecha del río Bernesga.

Presenta una planta rectangular definida por dos fosos (Fig. 18), separados entre sí por unos 2-2,5 m. El recinto no conserva el esquinal SE, que se pierde en el borde de la terraza, actualmente ocupado por una edificación. En la fotografía de 1956 se aprecia ya con claridad que en esa zona se sitúa el límite de la plataforma de la terraza, pero es difícil poder precisar si esto se debe a fenómenos erosivos más o menos recientes, o si ya en origen el recinto quedó inconcluso sobre el borde de la plataforma.

$\mathrm{Si}$ asumimos que el trazado de las estructuras responde a una planta regular, se observa que la extensión máxima del recinto -medida respecto al foso exterior- ocuparía un área de exactamente 4 actus quadratus.

\footnotetext{
${ }^{5}$ Recinto identificado por J. L. Pecharromán Fuente, a quien le damos las gracias.
} 

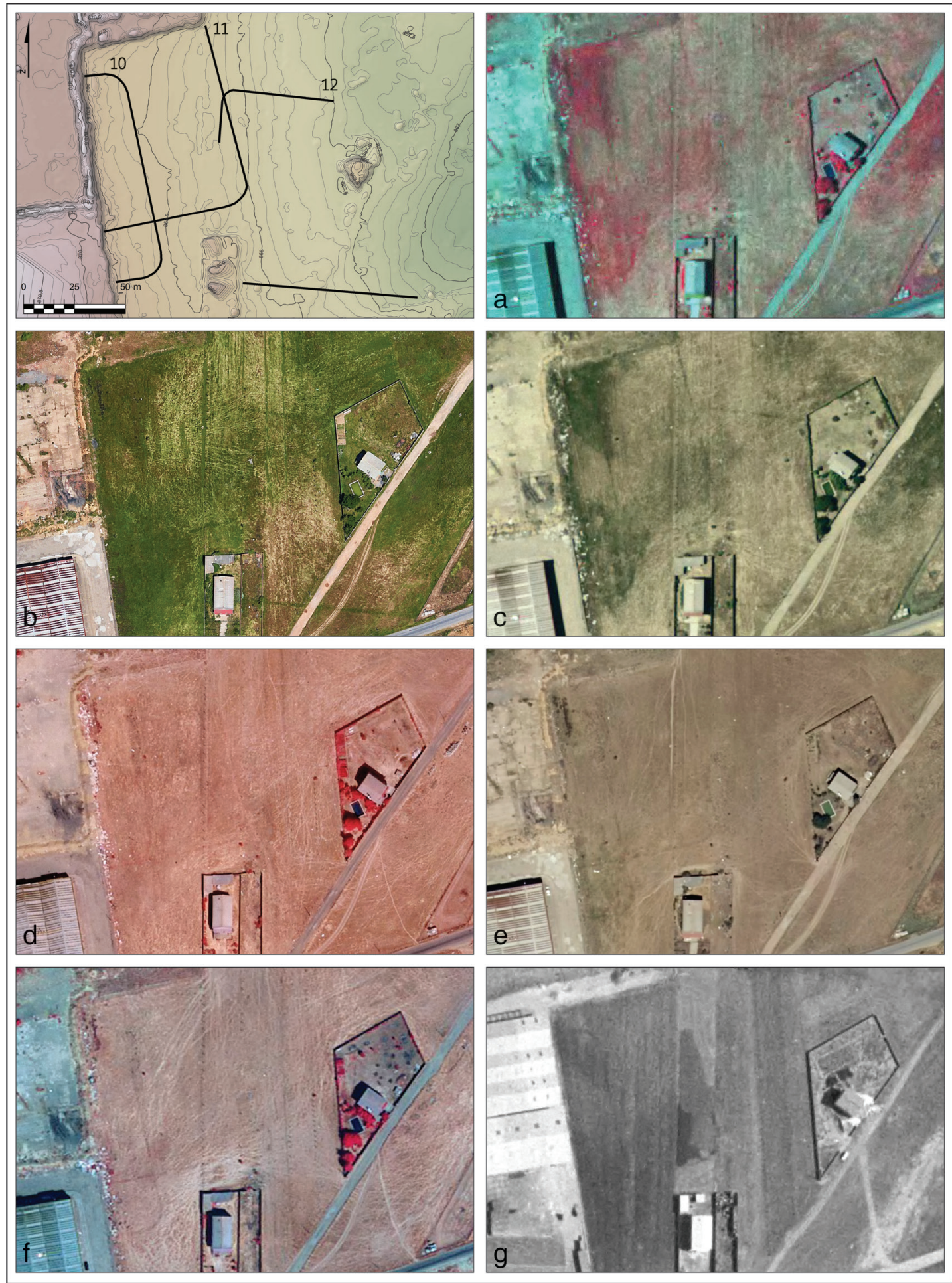

Figura 13. Recintos 10, 11 y 12. Curvas de nivel cada $10 \mathrm{~cm}$. a) PNOA 2011 falso color infrarrojo; b) Google Earth 2016; c) PNOA 2011; d) PNOA 2008 falso color infrarrojo; e) PNOA 2017; f) PNOA 2010 falso color infrarrojo; g) Interministerial 1973-1986. 


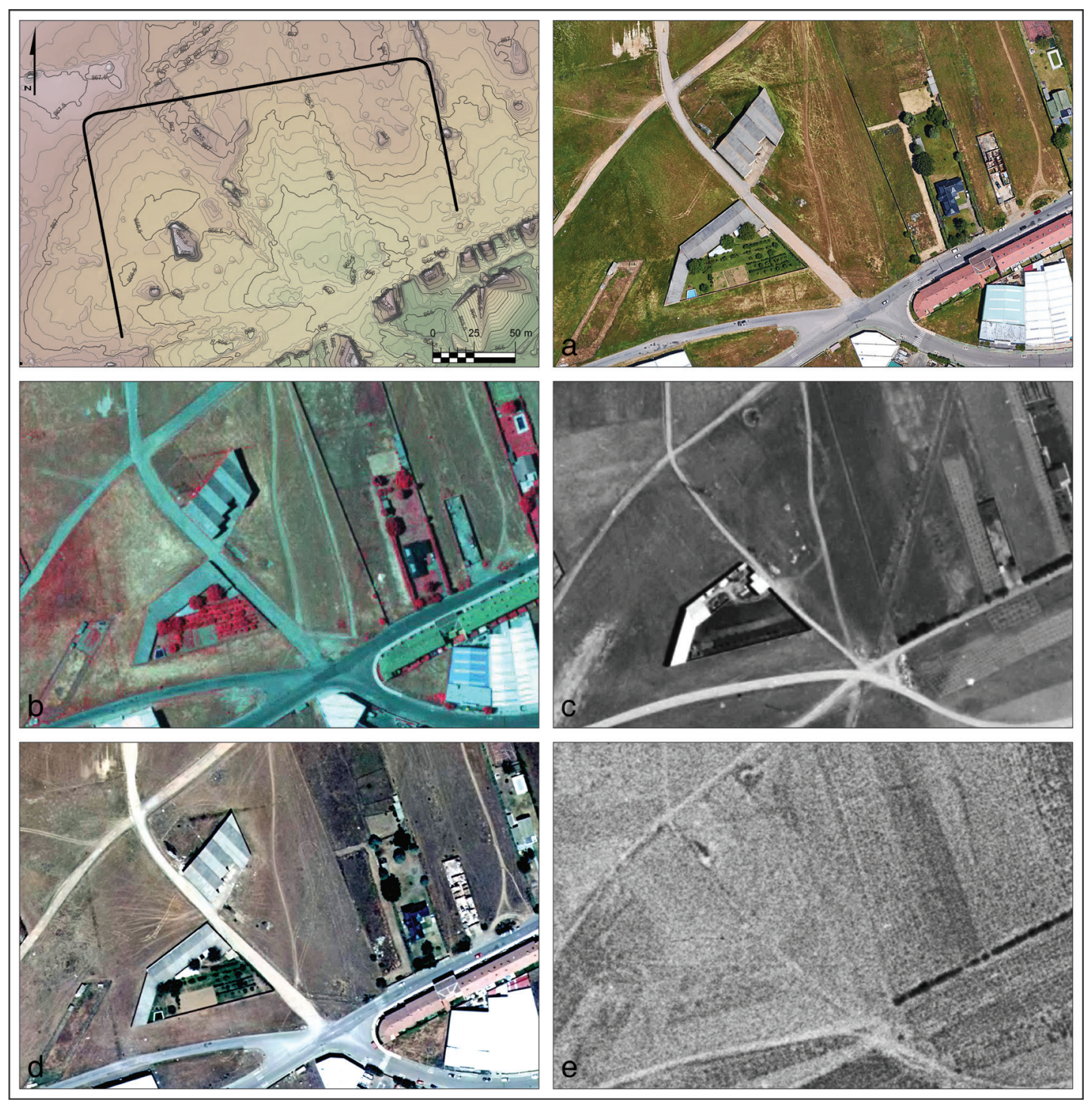

Figura 14. Recinto 13. Curvas de nivel cada $10 \mathrm{~cm}$. a) Google Earth 2016; b) PNOA 2011 falso color infrarrojo; c) Interministerial 1973-1986; d) PNOA 2017; e) USAF 1956.

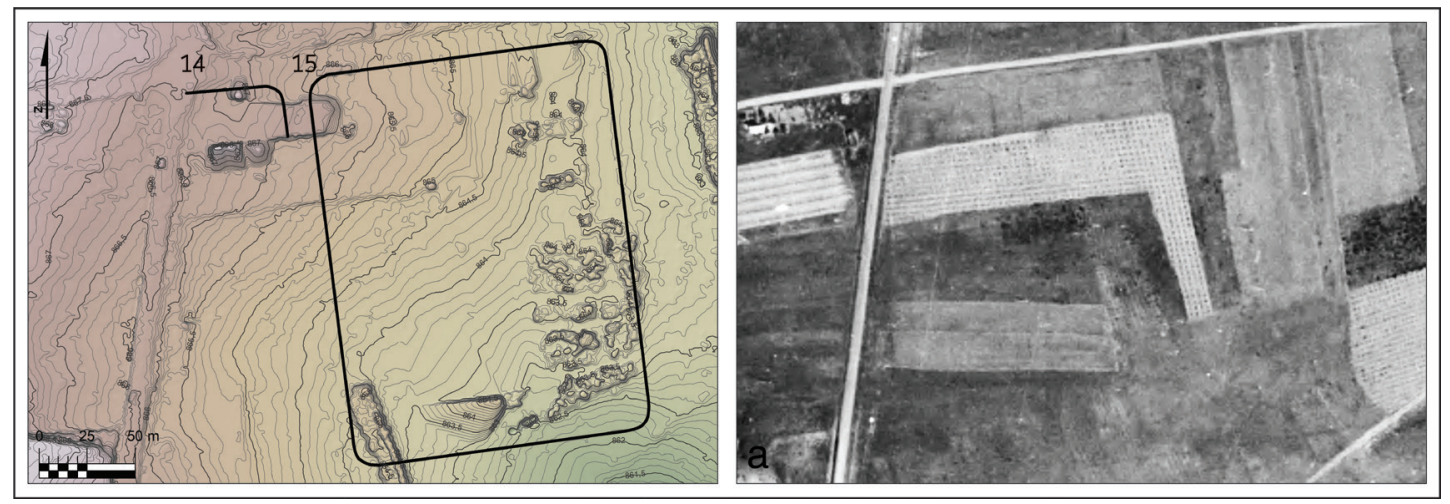

Figura 15. Recintos 14 y 15. Curvas de nivel cada $10 \mathrm{~cm}$. a) Interministerial 1973-1986. 


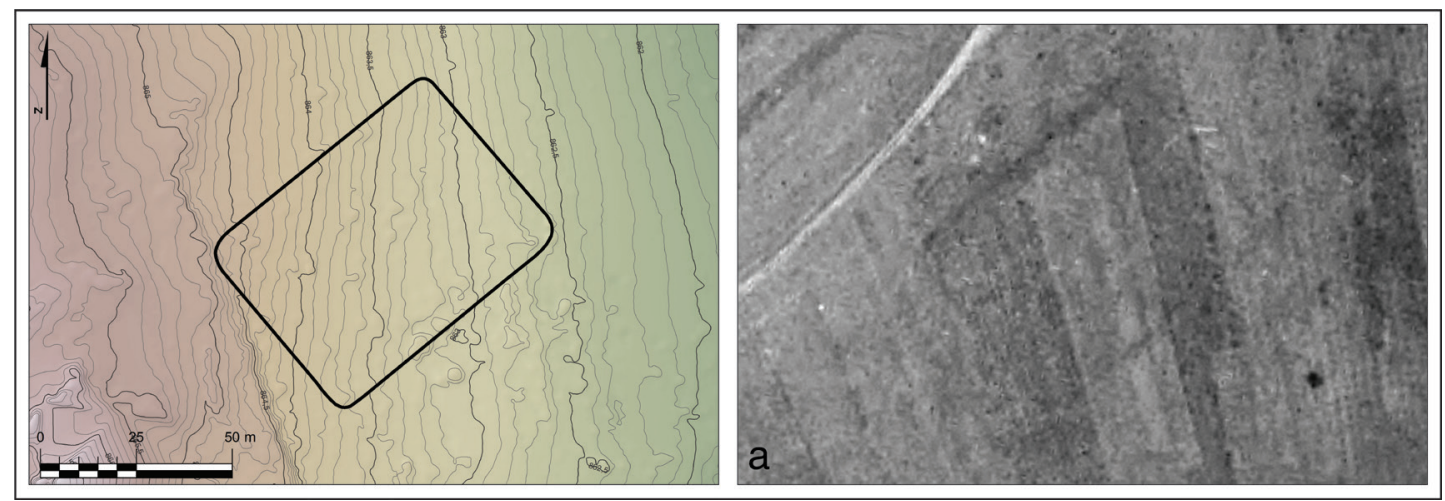

Figura 16. Recinto 16. Curvas de nivel cada $10 \mathrm{~cm}$. a) Interministerial 1973-1986.

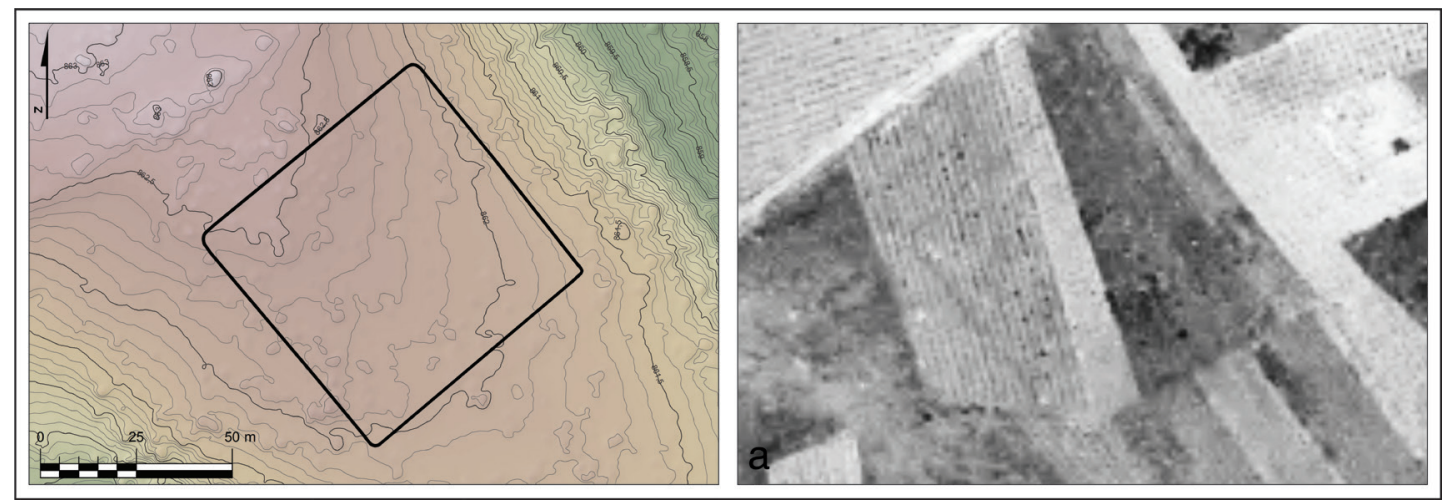

Figura 17. Recinto 17. Curvas de nivel cada $10 \mathrm{~cm}$. a) Interministerial 1973-1986.

\section{DESCRIPCIÓN LOCACIONAL}

El análisis computerizado mediante SIG de los parámetros locacionales de las estructuras documentadas en Rabanedo permite ir más allá de sus características formales e indagar en la estrategia que siguen los recintos en su forma de presentarse sobre el territorio. Para ello, tomamos como referencia tres parámetros fundamentales: visibilidad, visibilización y altura relativa.

La altura relativa permite evaluar la prominencia de un punto sobre el territorio, determinando si sobresale respecto al entorno o si por el contrario aparece oculto y poco destacado. Se calcula restando la altura media del entorno a la cota absoluta del punto analizado y dividiéndolo por la desviación típica. Hemos valorado la altura relativa respecto a un radio de $500 \mathrm{~m}$ que marca el entorno inmediato al campamento, y otro de $5 \mathrm{~km}$ que permite valorar la posición relativa en una mayor distancia.

La visibilidad determina la superficie visible desde un punto y expresa su capacidad de con- trol del territorio. Hemos calculado la visibilidad ${ }^{6}$ sobre un radio de $500 \mathrm{~m}, 1 \mathrm{~km}$ y $5 \mathrm{~km}$, lo que permite evaluar cuál es el dominio visual desde el entorno inmediato, hasta una cierta distancia?

La visibilización o prominencia visual determina cuán visible es un punto en el paisaje ${ }^{8}$. El

${ }^{6}$ Para el análisis de la visibilidad de cada campamento en lugar de partir de un punto hemos tomado como referencia la totalidad de su perímetro, lo que revela un resultado más matizado de lo que sería el control visual real desde el conjunto del recinto. El cálculo se ha establecido contando con una altura media de $1,7 \mathrm{~m}$ para el observador a la que se le han añadido 1,5 m como valor tipo del agger.

${ }^{7}$ El cálculo de la altura relativa y de la visibilidad se ha elaborado sobre un MDE de elevaciones con un paso de malla de $5 \mathrm{~m}$ obtenido de los datos LiDAR del PNOA.

${ }^{8}$ La visibilización se obtiene elaborando un mapa de "visibilidad total" resultante de la agregación de la visibilidad desde cada uno de los puntos del territorio. Para su cálculo hemos empleado el módulo de visibilidad de Quantum Gis (Čučković, 2016). Hemos partido de un MDE con un paso de malla de $25 \mathrm{~m}$. La extensión del área de análisis parte de un radio de $10 \mathrm{~km}$ respecto a los puntos analizados, lo que permite calcular la visibilización relativa respecto a $5 \mathrm{~km}$, evitando un 


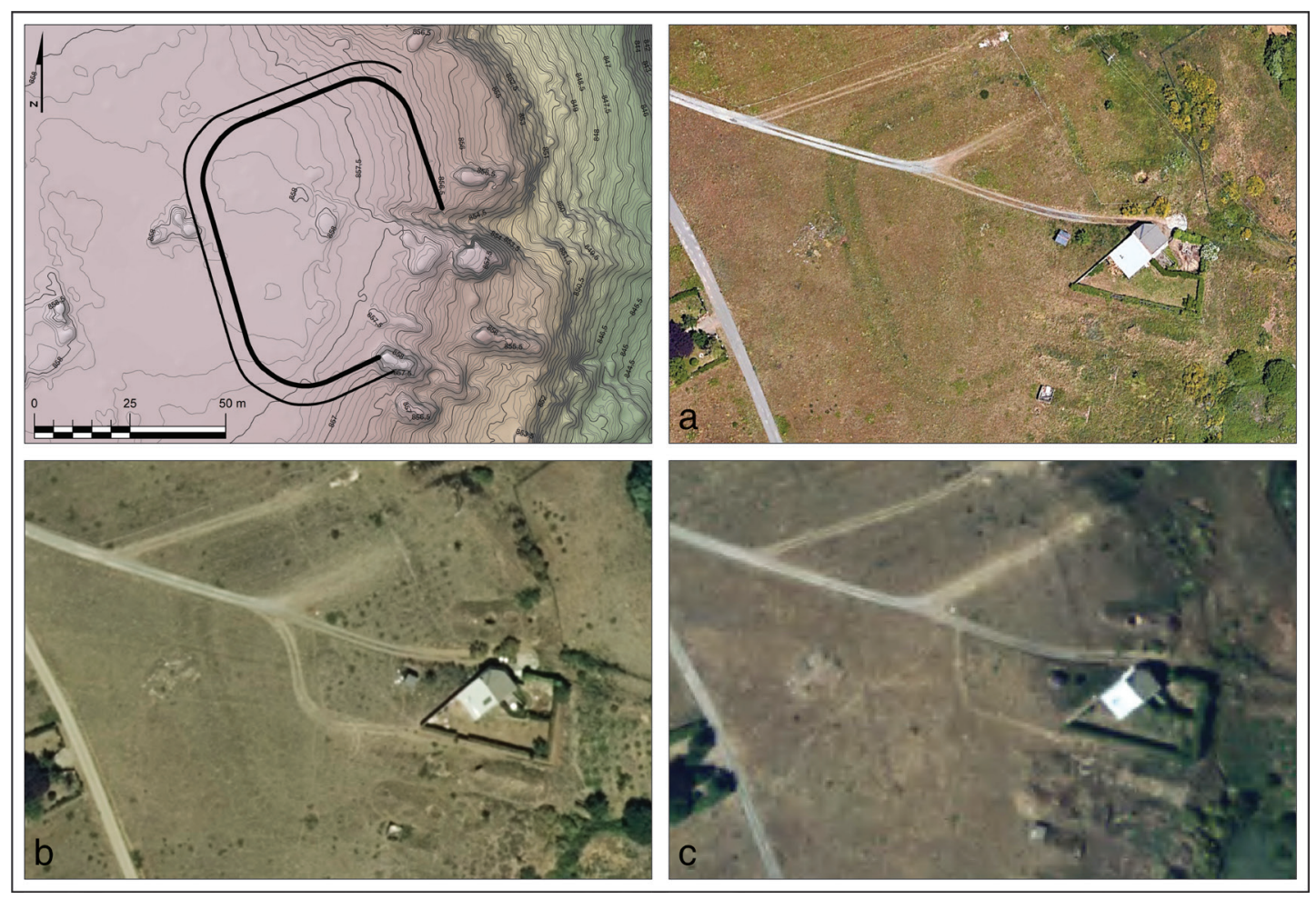

Figura 18. Recinto 17. Curvas de nivel cada 10 cm. a) Google Earth 2016; c) PNOA 2017; d) PNOA 2011.

valor absoluto obtenido tiene un significado muy limitado, por lo que evaluamos el resultado aplicando la misma fórmula con la que obtenemos la altura relativa, respecto a un radio de $1 \mathrm{~km}$ y de $5 \mathrm{~km}$. El valor resultante permite determinar si el punto de referencia destaca visualmente más o menos que su entorno.

Los resultados (Tab. 4) muestran un comportamiento locacional muy homogéneo para todos los recintos que componen el conjunto de Trobajo/Oteruelo y revelan que en la estrategia espacial que se esconde detrás de la elección del emplazamiento no parece haber primado ni el control del territorio, ni la vocación de distinguirse sobre el mismo ostentando una posición predominante.

La altura relativa en todos los intervalos presenta valores negativos o muy bajos. Tan solo destacan R-5, R-17 y R-18, que por su posición en el borde de la terraza sobresalen respecto al entorno más próximo. Lo mismo ocurre con los valores de visibilización, igual-

error por defecto motivado por el efecto borde. El cálculo parte de una malla de puntos equidistantes $25 \mathrm{~m}$ (total de 1.653 .388 puntos), para los que se calcula la visibilidad sobre un radio de $5 \mathrm{~km}$ con una altura de observación de 1,7 m. mente con cifras negativas para prácticamente todos los casos, tanto respecto a 1 como a $5 \mathrm{~km}$.

Los recintos castrenses controlan visualmente prácticamente todo su entorno más próximo, con una visibilidad sobre el intervalo de $500 \mathrm{~m}$ que domina como media el $79 \%$ de la superficie (Fig. 19). Estos valores demuestran que desde los campamentos se consigue ver la plataforma allanada de la terraza. Sin embargo, a medida que se amplía el intervalo de referencia, la superficie visible se

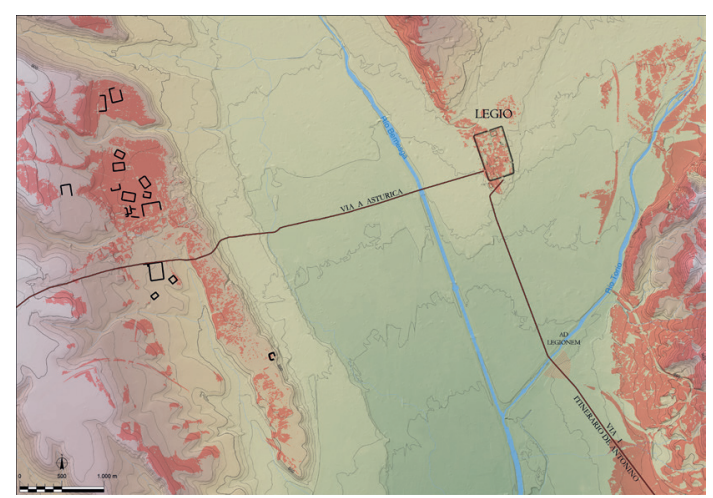

Figura 19. Superficie visible desde R-1. 
Tabla 4. Valores de los parámetros locacionales.

\begin{tabular}{|c|c|c|c|c|c|c|c|}
\hline SIGLA & $\begin{array}{c}\text { altura } \\
\text { relativa a } \\
500 \mathrm{~m}\end{array}$ & $\begin{array}{c}\text { altura } \\
\text { relativa } \\
\text { a } 5 \mathrm{~km}\end{array}$ & $\begin{array}{c}\% \text { de } \\
\text { superficie } \\
\text { visible a } \\
500 \text { m }\end{array}$ & $\begin{array}{c}\% \text { de } \\
\text { superficie } \\
\text { visible a } \\
1 \text { km }\end{array}$ & $\begin{array}{c}\% \text { de } \\
\text { superficie } \\
\text { visible a } 10 \\
\text { km }\end{array}$ & $\begin{array}{l}\text { visibiliza- } \\
\text { ción } \\
\text { relativa a } \\
1 \mathrm{~km}\end{array}$ & $\begin{array}{c}\text { visibiliza- } \\
\text { ción } \\
\text { relativa a } \\
5 \mathrm{~km}\end{array}$ \\
\hline R-1 & $-0,58$ & $-0,07$ & 88,1 & 36,5 & 6,1 & $-0,48$ & $-0,56$ \\
\hline $\mathrm{R}-2$ & $-0,05$ & $-0,05$ & 89,8 & 41,1 & 8,7 & 0,00 & $-0,08$ \\
\hline $\mathrm{R}-3$ & $-0,29$ & $-0,08$ & 93,0 & 48,8 & 6,9 & $-0,35$ & $-0,33$ \\
\hline $\mathrm{R}-4$ & $-0,11$ & $-0,08$ & 97,2 & 47,8 & 7,2 & $-0,30$ & $-0,24$ \\
\hline R-5 & 0,45 & $-0,11$ & 61,6 & 39,9 & 11,9 & $-0,23$ & $-0,15$ \\
\hline R-6 & $-0,29$ & $-0,15$ & 63,0 & 29,9 & 8,1 & $-0,66$ & $-0,55$ \\
\hline $\mathrm{R}-7$ & $-0,18$ & 0,22 & 69,8 & 41,6 & 9,6 & $-0,59$ & $-0,72$ \\
\hline R-8 & $-0,53$ & $-0,06$ & 77,8 & 36,3 & 6,0 & $-0,44$ & $-0,52$ \\
\hline R-9 & $-0,18$ & $-0,04$ & 80,1 & 35,2 & 7,7 & $-0,25$ & $-0,34$ \\
\hline R-10 & $-0,43$ & $-0,02$ & 67,5 & 31,4 & 6,5 & $-0,42$ & $-0,58$ \\
\hline $\mathrm{R}-11$ & $-0,54$ & $-0,05$ & 74,6 & 33,0 & 6,7 & $-0,70$ & $-0,79$ \\
\hline $\mathrm{R}-12$ & $-0,51$ & $-0,04$ & 72,4 & 32,9 & 6,2 & $-0,46$ & $-0,60$ \\
\hline $\mathrm{R}-13$ & $-0,36$ & $-0,04$ & 88,0 & 41,3 & 9,6 & $-0,80$ & $-0,82$ \\
\hline R-14 & $-0,31$ & 0,04 & 72,6 & 41,5 & 6,8 & $-0,29$ & $-0,65$ \\
\hline R-15 & $-0,11$ & 0,03 & 92,1 & 48,2 & 7,0 & $-0,23$ & $-0,53$ \\
\hline R-16 & $-0,14$ & 0,05 & 69,8 & 42,7 & 5,9 & $-0,12$ & $-0,56$ \\
\hline R-17 & 0,25 & 0,05 & 83,8 & 45,1 & 5,9 & $-0,09$ & $-0,35$ \\
\hline $\mathrm{R}-18$ & 1,04 & 0,36 & 68,4 & 50,3 & 17,9 & 1,23 & 1,60 \\
\hline Legio & 1,17 & $-0,43$ & 100 & 100 & 15,5 & 0,93 & 0,91 \\
\hline
\end{tabular}

diluye. Si pasamos de $500 \mathrm{~m}$ a $1 \mathrm{~km}$ el porcentaje de tierra visible se reduce a una media del $39 \%$. Sobre $10 \mathrm{~km}$ tan solo se controla visualmente el $7,5 \%$ de la superficie. La cuenca visual respecto a la larga distancia se presenta de forma difusa y no existe un control efectivo del valle. Pero, aunque la visibilidad es limitada, sí que existe una tendencia a la intervisibilidad con Legio que se observa en todos los casos, excepto en R-16 y R-17.

$\mathrm{Si}$ introducimos en el análisis un elemento externo de contraste conseguimos que los resultados del estudio locacional de los recintos campamentales sean más expresivos. Así, comprobamos cómo la ciudad de Legio, situada en un punto estratégico sobre la confluencia de los ríos Bernesga y Torío, despliega un amplio dominio visual sobre el valle y ocupa una posición destacada sobre su entorno, que contrasta intensamente con los indicadores de los recintos estudiados (Fig. 20).

Los resultados del análisis locacional muestran que el emplazamiento escogido no permite destacar sobre el paisaje, ni ejercer un control eficaz del territorio. La lógica que subyace en la elección de esta localización para la construcción de los recintos debe responder, por lo tanto, a otros factores, que quizás tengan más que ver con las necesidades del proceso de construcción de los recintos y su relación con Legio, que propiamente con su posición estratégica. Como ve-

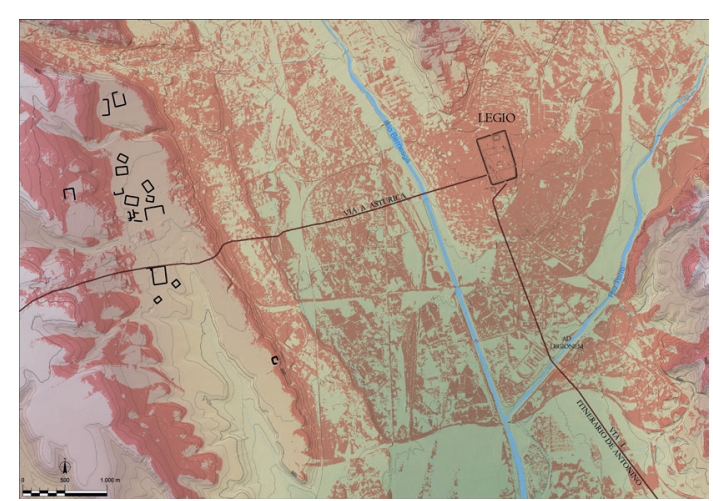

Figura 20. Superficie visible desde Legio. 
remos, el paso de la vía que comunica Legio y Asturica Augusta es sin duda determinante. Saliendo desde el campamento de León, siguiendo el recorrido de la vía, la plataforma que forma la terraza sobre el río Bernesga es el lugar que reúne unas mejores condiciones para levantar los recintos con mayor facilidad. Un espacio llano $\mathrm{y}$ bien nivelado, con un suelo pobre en el que nunca debió de ser abundante la vegetación y que siempre sería más cómodo que la zona del fondo del valle, en donde habría una vegetación más espesa, que tendría que ser roturada, y unos suelos, más pesados y húmedos, en los que sería más dificultoso abrir las zanjas de las fossae. Un lugar apartado de la ciudad, del suburbio y de los asentamientos rurales de la periferia, pero a la vez bien comunicado. Un lugar sobre el que además existe un control visual desde los muros de la ciudad, pues aunque desde Legio no se alcanza a ver la superficie de la plataforma (situada a una cota unos $30 \mathrm{~m}$ más elevada), sí se divisa a la perfección el borde la terraza y el conjunto del emplazamiento.

\section{LOS CAMPAMENTOS DE PRÁCTICAS O MANIOBRAS Y EL COMPLEJO DE TROBAJO DEL CAMINO/OTERUELO DE LA VALDONCINA. IDENTIFICACIÓN E INTERPRETACIÓN}

A la vista de las características morfológicas de este conjunto de recintos campamentales más o menos completos, de su emplazamiento y de la relación con Legio, todo indica que se trata de una serie de estructuras resultado del entrenamiento de las tropas en tareas de castrametación. La existencia de campamentos para prácticas ha sido una cuestión a menudo soslayada en los estudios sobre Arqueología Militar, si bien recientemente ha recibido una mayor atención, ya que constituyen documentos de enorme interés de cara al conocimiento de las actividades del ejército romano en tiempos de paz (Schnurbein, 2006: 138; Jones, 2017: 523-524). Se emplean para entrenar a los soldados en el atrincheramiento de campamentos, la excavación de fosos y elevación de terraplenes y empalizadas, que conforman el sistema defensivo de los campamentos (agger), particularmente complejo en los ángulos redondeados, y las entradas (titula y claviculae).

La castrametación era un parte importante de la formación y de la disciplina militar, encargada a los denominados metatores y mensores ${ }^{9}$. Se consideraba reflejo de la eficacia y la organización del ejército de Roma y de ahí que fuese practicada regularmente. Los tratados antiguos dejan constancia no solo de la importancia estratégica o para la seguridad de la construcción de los campamentos, sino también de su alto valor simbólico del poder imperial, del orden y la disciplina militaris (Veg. I, 24, 1-5; I, 25, 1-5; III, 8, 1-3). Exigía un trabajo colectivo y coordinado, y se relaciona con el mantenimiento de la moral y la identidad, con el orden y la jerarquía (Phang, 2008: 67-70).

Tanto el ejército estabilizado en campamentos, como el ejército en maniobras (ambulatio), tal y como explica Vegecio (I, 25-27), tenía entre sus obligaciones regulares efectuar prácticas de castrametación. Es bien conocido el pasaje de Apiano sobre la guerra numantina (Iber. 86) donde relata el exhaustivo entrenamiento del ejército, dentro del que desempeñaba un papel fundamental la construcción y demolición de campamentos. Esta misma idea aparece en Séneca ${ }^{10}$. Vegecio establece que los fosos para campamentos de marcha o entrenamiento deben tener unas dimensiones estándar de $9 \times 7$ pies romanos $(2,66 \mathrm{~m}$ de anchura x $2 \mathrm{~m}$ de profundidad), mientras el terraplén debe ser de unos 3 pies de altura (0,90 m) (Veg. I, 23).

Además de los aspectos constructivos mencionados más arriba, la castrametación implicaba práctica en otros dos aspectos: la orientación y la modulación. Ambos requerían el recurso a conocimientos e instrumentos topográficos.

\footnotetext{
9 «Metatores qui praecedentes locum eligunt castris. (...) Mensores qui in castris ad podismum demetiuntur loca, in quibus tentoria milites figant, uel hospitia in ciuitatibus praestant» (Veg. II, 7). «Los metatores son quienes van adelantados, con el fin de elegir emplazamiento para el campamento (...). Los mensores son quienes dentro del campamento realizan las mediciones de los lugares en que los soldados montan las tiendas y quienes se responsabilizan de encontrar acomodo en las ciudades» (traducción de D. Paniagua Aguilar, Flavio Vegecio Renato, Compendio de técnica militar, Madrid, Cátedra, 2006).

${ }_{10}$ «Miles in media pace decurrit, sine ullo hoste vallum iacit, et supervacuo labore lassatur ut sufficere necessario possit; quem in ipsa re trepidare nolueris, ante rem exerceas» (Ep. XVIII, 6). «En tiempos de paz, el soldado realiza maniobras, construye trincheras sin enemigo a la vista y se fatiga con trabajos inútiles, para estar a la altura en los trabajos necesarios. Si no se quiere que un hombre tiemble cuando llegue una crisis, debe estar entrenado antes» (a partir de la traducción de R. M. Gummere, en Seneca the Youger, Epistoles Volume I: Epistles 1-65, Loeb Classical Library, 1917).
} 
Los textos antiguos indican que era importante la capacidad de adaptar las proporciones a las situaciones (Veg. I, 21). Llevar a cabo el adiestramiento de tropas era imprescindible, partiendo de la unidad básica del ejército romano o contubernium (8 soldados), a quien se le encomienda la erección de un sector pre-asignado de las defensas. Se requiere un resultado satisfactorio de su trabajo en un determinado tiempo, lo que permite la rápida construcción de un recinto castrense en caso de campaña o marcha. Además, el trabajo de cada grupo de 8 soldados debe saber combinarse con el efectuado por los soldados de otros barracones o contubernia, que forman parte de la misma centuria, aprendiendo a actuar coordinados. En caso de campamentos construidos apresuradamente frente al enemigo, las centurias se llaman por turnos mediante relevos (Veg. II, 25). Una unidad mayor requerirá un campamento más grande, precisamente porque al ser mayor el número de soldados podrán trabajar en un perímetro más extenso. Bajo las órdenes del praefectus castrorum (Veg. II, 10, 1), los campi doctores enseñan asimismo a orientar los recintos. En definitiva, se plasma en estructuras sobre el terreno, la configuración modular del ejército romano desde una profunda racionalización del trabajo y un acusado pragmatismo.

Se sabe de varios conjuntos de campamentos para prácticas. Los primeros en darse a conocer se localizaron en la Germania Inferior, cerca de los campamentos legionarios de Bonna (Bonn-Kottenforst) (Scollar, 1965; Scollar y AndrikopoulouStrack, 1984; Bödecker, 2012) y Vetera Castra I (Alpen-Veen-Menzeler, cerca de Xanten) (Hinz, 1984; Horn, 1987: 332-334, fig. 279 y 280; Bödecker, 2013, 2014). Este último conjunto es uno de los mejor conocidos, con medio centenar de recintos más o menos completos, a veces simples alineamientos o esquinas con diferentes orientaciones, dispuestos a ambos lados de la vía romana, a media jornada de marcha desde los castra legionarios. Identificados a través de fotografía aérea, se extienden por una superficie de unos $10 \mathrm{~km}^{2}$. No existen elementos para proponer una datación.

Otro de los casos más conocidos se localiza en Pannonia, también junto a la fortaleza legionaria de Brigetio (Komáron, Hungría). En este caso, la prospección aérea, combinada con la verificación posterior sobre el terreno, reveló la existencia de 19 recintos más o menos completos en sus alrededores, de los cuales algunos parecen fuertes temporales, mientras que otros, que se superponen (por ejemplo VII, IX, X y XI), podrían interpretarse como campamentos para prácticas (Visy, 2003: 3438, fig. 36 a 55b; Számado-Borby, 2003: 78-79).

Hay varios ejemplos de la concentración de este tipo de trabajos de entrenamiento en Gales. Los cuatro de Llyn Hiraethlyn, a unos $4 \mathrm{~km}$ al sudeste del campamento principal de Tomen y Mur (Merioneth, norte de Gales), descubiertos en 1996 (Driver et alii, 1997), se vinieron a sumar a otros grupos de estructuras ya conocidas, como los 5 de Dolddinas ( $3 \mathrm{~km}$ al SSE del campamento principal). Aún en 2001 se descubrieron los de Dolbelydr, al norte del recinto de Mur-llwyd. El número de estructuras llega a una quincena, todas relacionados con el campamento de Tomen y Mur. El origen de este conjunto castrense se ha puesto en relación con las campañas de Agricola en el noroeste de Gales (77-78 d. C.) y hay referencias a una reducción de las dimensiones del campamento y reconstrucción de Tomen y Mur bajo Adriano hacia el 120 d. C. Es un excelente ejemplo del uso de fotografía aérea (St. Joseph, 1977: 151; Lynch, 1995: 108-109; Musson, 1994: 86-87; Crew y Musson, 1996: 26-30; Burnham et alii, 1997, 397-399, fig. 4; Davies y Jones 2006; Burnham y Davies, 2010; Jones, 2011, 2012). Hay restos de estructuras superpuestas e inconclusas al sudeste del campamento.

También en Gales, en Llandrindod Wells (Radnorshire), al sur del campamento de Castell Collen, hay 22 pequeños fuertes y fortines, algunos de ellos auténticas miniaturas para la práctica de puertas (Jarrett y Nash-Williams, 1969: 126; Davies y Jones, 2006). También en las proximidades de los establecimientos militares de Chester y York hay recintos de estas características con entre 0,9 y 2,2 ha, interpretados como campamentos de prácticas o/y para alojamiento de tropas en maniobras (Philpott 1988; Welfare y Swan, 1995: 135; Johnston, 2003; Davies y Jones 2006: 143146). Resulta muy difícil distinguir ambos tipos (Jones, 2017: 523).

Hay en Hispania varios conjuntos que pensamos pueden revisarse desde esta óptica. Sin salir del noroeste, podrían encajar dentro de esta misma categoría los recintos localizados hace varias décadas $3 \mathrm{~km}$ al suroeste de Castrocalbón (León), a ambos lados de la vía XVII del Itinerario de Antonino (Loewinsohn, 1965). Este investigador identifica tres recintos de entre 1,4 y 4 ha, poniéndolos en relación con la cohors IV Gallorum, ya que cerca de este lugar apareció un depósito de hitos terminales de época de Claudio en los que 
se mencionaba a esta unidad. Recientemente se han añadido nuevas alineaciones en el terreno que parecen definir un cuarto y quinto recinto (Costa García, 2016: 58-59). Jones los clasifica como campamentos para prácticas (1976: 59), cuestión que puntualiza Le Roux (1982: 107-108), que los considera, por su tamaño mayor, más campamentos de maniobras que recintos de aprendizaje. Algunos de los recintos de Villamontán de la Valduerna (Celis et alii, 2016) recientemente documentados y todavía inéditos, quizás también puedan asimilarse con este modelo de prácticas de castrametación. Situados a $19 \mathrm{~km}$ de Asturica Augusta y a 15 de Castrocalbón, aparecen también articulados en función del paso de la vía XVII, dispuestos a ambos lados de la calzada. Lo mismo podría ocurrir en el conjunto campamental de A Chá de Santa Marta (Orejas et alii, 2015, 2019), muy próximo al paso de la vía que comunica $L u$ cus Augusti y Dactonium, recogida en el Itinerario de Barro (Fernández Ochoa et alii, 2012: 164). Tal vez otros conjuntos de varios recintos campamentales y alineamientos de antiguos fosos en el terreno, como los de La Matilla (Herramelluri, La Rioja), situado junto a un cruce de vías en las cercanías de la ciudad romana de Libia (Didierjean et alii, 2014: 166-168) puedan también responder a una casuística semejante ${ }^{11}$. En todos los casos, con las evidencias conservadas es difícil determinar si estamos ante desplazamientos de guarniciones, operaciones de maniobras o estructuras construidas como parte de las prácticas. Lo que sí parece claro es que el vínculo con el sistema viario es una constante en este tipo de instalaciones militares.

$\mathrm{Si}$ en el caso de los recintos más pequeños está excluido pensar en una ocupación, en el caso de los mayores no es imposible que se utilizasen también para hacer en su interior prácticas de otras operaciones (por ejemplo, montar o desmontar tiendas o trazar la ordenación interna del espacio "a escala") o incluso que se acampase en maniobras. En las excavaciones en Monk's Cross, recinto cercano a York, se han encontrado en el interior huellas de postes y algunas alteraciones, quizás relacionadas con el campamento, aunque no se han datado (Johnston, 2003). Algo común a todos estos grupos relacionados con prácticas es su detección gracias a la fotografía aérea en dis-

11 Este podría ser asimismo el caso de varios recintos ubicados al suroeste y noreste del campamento de Herrera de Pisuerga (Palencia) que se han dado a conocer hace pocos meses (Martín Hernández et alii, 2020: esp. 50-53). tintos momentos (Scollar, 1965; St. Joseph, 1977; Lynch, 1995).

A juzgar por los ejemplos que conocemos, este tipo de recintos castrenses cumple una serie de características fundamentales:

- Cercanía a un enclave militar importante, en el que estarían alojadas las unidades militares.

- Proximidad a una vía, que articula y estructura la disposición de los campamentos

- Una alta densidad de restos en un espacio limitado.

- Reducido tamaño de los recintos.

- Trabajos específicos sobre zonas cuya construcción es especialmente dificultosas: las esquinas redondeadas (coxae).

- Ubicación en suelos pobres, apartados de las zonas de fondo de valle, con escasa utilidad agrícola y, en la medida de lo posible, bien drenados.

Si bien en ocasiones la diferenciación respecto a los campamentos de etapa o marcha no es evidente desde el punto de vista estructural, la convergencia de estos rasgos es muy concluyente. Todos ellos se verifican en el conjunto de recintos militares que aquí presentamos. Son estructuras con planta de naipe y con una sola fosa aparentemente. Los recintos con el perímetro completo, o casi completo, presentan unas superficies que van entre las aproximadamente 2 y las 0,4 ha. Una de las características de estos campamentos suele ser su reducido tamaño. Los galeses citados más arriba son realmente pequeños: miden entre 0,02 y 0,4 ha y en varios casos está claro que el punto de interés eran las entradas. Se constatan asimismo varios segmentos de recintos, de los cuales posiblemente algunos responden a prácticas centradas en la construcción de esquinas (R-6, 7, 8, 10, 11, 12, 13, 14).

Aunque todavía es necesario procesar mejor los datos y contrastarlos sobre el terreno, las referencias obtenidas por ahora permiten avanzar que se practicaban módulos fácilmente identificables (sobre todo 3:2, también 4:3 y 1:1 en un caso). El módulo más habitual $(3: 2)$ corresponde al modelo canónico de campamento posterior a la reforma de Mario, tres partes de longitud por dos de anchura, cuyos primeros ejemplos, aún con esquinas en ángulo recto, se verifican en época sertoriana (Morillo y Sala, 2019: 60). Ya hemos apuntado que este modelo no se generalizará hasta mediados del siglo I a. C.

Otro de los aspectos que no deja lugar a dudas es su conexión con el tramo de la vía romana que, 
procedente de Legio, se dirige en dirección a $A s-$ turica Augusta. El trazado concreto de este recorrido fue dado a conocer ya a finales del siglo XIX por el ingeniero Martínez González, que lo hacía coincidir con el antiguo Camino de la Raya, cerca de Trobajo del Camino, que en la actualidad separa los términos municipales de León y San Andrés del Rabanedo (Martínez González, 1874). Esta información se conserva en un manuscrito inédito que hemos podido consultar en la Real Academia de la Historia, que también ha sido empleado por Moreno Gallo para definir el trazado (Moreno Gallo, 2011-2017) (v. Fig. 1). Desde los alrededores de la Virgen del Camino la actual pista sin asfaltar, sin duda coincidente con la vía romana, se separa del Camino de Santiago y atraviesa una planicie desde la cual se visualiza ya todo el valle del Bernesga, para descender una suave pendiente y tomar el camino de la Vega, atravesando el barrio de la Sal para cruzar el Bernesga y penetrar en el antiguo campamento. Muy cerca de Trobajo del Camino, Martínez González (1874: s/p) apunta la existencia de ruinas romanas que fueron visitadas por F. Fita, que se extendían por una extensión de unos $400 \mathrm{~m}$ de longitud por 200 de anchura.

De cualquier manera, el complejo militar se ubicaría a algo menos de media jornada de marcha desde la base legionaria y al lado de una vía, al igual que el complejo de Vetera Castra (Horn, 1987: 332-334, figs. 279 y 280).

Por lo que se refiere a la orientación de los recintos, parece que es precisamente la vía la que actúa como eje estructurante. Es claro en el caso de los recintos R-14 y R-15, que se sitúan perfectamente paralelos al trazado de la vía, de la que quedan separados por escasos metros. El resto de las estructuras, aparentemente se articulan en función de un eje perpendicular a la vía que recorre la plataforma de norte a sur. Los recintos quedarían así divididos por un camino, a un lado R-1, 3, 4, 6, $8,10,11$ y 12 , y al otro R-2, 5, 9 y 13 . La estructuración de los campamentos sugiere la existencia de ese camino derivado de la vía, aunque no se han documentado trazos claros,

Uno de los aspectos más significativos es su conexión visual con Legio, situado justo al este y controlando todo el campo de maniobras de castrametación ubicado en esta plataforma natural muy cercana a Trobajo del Camino, sin duda es uno de los lugares que reúne mejores condiciones para un establecimiento de este tipo. No cabe duda de que su localización en este lugar se encuentra directamente relacionada con la presen- cia del campamento legionario. El primer asentamiento por parte de la legio VI victrix en el cerro que se levanta en el interfluvio entre el Bernesga y el Torío tuvo lugar en torno al cambio de Era. A este primer campamento augusteo, construido en madera y tierra, le sustituyó hacia el 15/16 d. C. un segundo recinto, León II, ya rectangular con esquinas redondeadas, prácticamente idéntico al posterior, edificado por la legio VII gemina (Morillo y García Marcos 2006: 231-232; Morillo 2012: 227-228). En torno al 74/75 d. C., dicha unidad, refundada tras las guerras civiles del 68-69 d. C. como VII gemina, construye un campamento de nueva planta con defensas en piedra y terraplén interior, reaprovechando de forma selectiva las estructuras defensivas del recinto precedente. Las excavaciones llevadas a cabo durante los últimos veinte años en el casco urbano han permitido conocer numerosos aspectos del campamento flavio, que sigue el modelo canónico de planta rectangular con esquinas oblongas y grandes puertas en cada uno de los costados (García Marcos, 2002: 189-195; Morillo, 2012: 237). A partir de este momento León será la principal base militar de operaciones a lo largo de todo el Imperio. Su impacto en el territorio circundante, tanto el adscrito directamente a su jurisdicción o leuga (Morillo y Durán Cabello, 2017: 526-528; Morillo et alii, 2018: 176-177; Morillo y García Marcos, 2020) como el que se extendía más allá, será intenso, generando formas de ocupación del paisaje peculiares, como el vicus militaris, puestos de control o campamentos de prácticas o maniobras.

Finalmente, uno de los aspectos más complejos de determinar es el de la cronología de este complejo. Tan solo contamos con la propia morfología de los recintos, rectangulares y con esquinas redondeadas, forma que, como ya hemos señalado, se generaliza como tal en torno a las décadas centrales del siglo I d. C. De hecho, el propio campamento tiberiano de León es uno de los primeros donde se verifica dicha planta, continuada luego a partir del periodo flavio en una nueva fortaleza legionaria. Estamos por lo tanto ante un marco temporal amplio que iría desde Tiberio hasta las primeras décadas del siglo III d. C. Solo una prospección sistemática del terreno como la que abordaremos en los próximos años podrá tal vez proporcionar algún indicio cronológico, aunque al tratarse de yacimientos efímeros es poco probable que encontremos restos materiales que pudieran ayudar a fecharlos. 
La identificación y documentación de este conjunto de recintos abre algunas vías de trabajo sobre las que la investigación prosigue y que incorporarán, necesariamente, el trabajo sobre el terreno. Por una parte, proporciona la ocasión de documentar aspectos técnicos de la metatio: medidas y modulaciones, orientaciones/varatio y soluciones geométricas, como el trazado de coxae). Los datos recogidos permiten constatar la existencia de regularidades sobre las que establecer interpretaciones más ajustadas.

Por otro lado, permite considerarlos desde la óptica de la disciplina castrense y la organización del trabajo. Esta regularidad morfológica no solo tiene que ver con la estandarización formal de las plantas de los campamentos, sino también con la asignación de tramos del perímetro a grupos de soldados determinados, posiblemente contubernia.

\section{P. S. ACLARACIÓN SOBRE LA ORIGINALIDAD DE ESTE ARTÍCULO}

Durante el proceso de evaluación de este artículo en Gladius tuvimos conocimiento de la publicación de un trabajo en la revista Geosciences que incluye datos coincidentes con los que damos a conocer en estas líneas. Dicho trabajo [A. Menéndez et alii, «Following the Roman Army between the Southern Foothills of the Cantabrian Mountains and the Northern Plains of Castile and León (North of Spain): Archaeological Applications of Remote Sensing and Geospatial Tools», Geosciences 2020, 10, 485] fue enviado a Geosciences el 19 de octubre de 2020, según consta en dicha publicación. El artículo que aquí presentamos, fruto de investigaciones de los firmantes desarrolladas entre 2019 y 2020, había sido presentado en Gladius el 27 de mayo de 2020, como consta en esta publicación. Un avance de nuestros resultados fue divulgado también en los medios de comunicación el 17 de julio de 2020. Queremos con esta nota señalar que nuestras investigaciones eran inéditas en la fecha en la que fueron presentadas a Gladius.

\section{BIBLIOGRAFÍA}

Bödecker, S. (2012): «Römische Übungslager im Hinterland von Bonn», Der Limes vom Niederrheim bis an die Donau. Sttutgart, Konrad Theis: 21-27.
Bödecker, S. (2013): «Ein Übungslagerareal im Hochwald bei Uedem», Der Limes. Schwerpunkt Denkmalvermittlung und Nachbauten 7, 2: 10-13.

Bödecker, S. (2014): «Airborne Laserscanning am Niedergermanischen Limes. Ein Úbungslagerareal im Hochwald Xanten», P. Henrich (ed.), Der Limes in Raetien, Ober- und Niedergermanien vom 1.bis 4. Jahrhundert, 8. Darmstadt, Konrad Theiss: 187191.

Burnham, B. C. y Davies, J. L. (eds.) (2010): Roman frontiers in Wales and the Marches. Aberystwyth, CBHC.

Burnham, B. C.; Keppie, L. J. F.; Esmonde Cleary, A. S. y Tomlin, R. S. O. (1997): «Roman Britain in 1996». Britannia, 28: 395-472. https://doi. org/10.2307/526780

Celis Sánchez, J.; Muñoz Villarejo, F. y Valderas Alonso, F. (2016): «Núcleos romanos en torno a la Vía XVII. Los campamentos de Villamontán y la mansio de Argentiolum», III Jornadas Internacionales Evolución de los espacios urbanos y sus territorios en el Noroeste de la Península Ibérica, 22 de abril de 2016, Astorga (inédito).

Cordero, T.; Cerrillo, E. y Pereira, C. (2017): «Detección de un nuevo campamento romano mediante tecnología LiDAR en las inmediaciones de Mérida». Saguntum, 49: 197-201. https://doi. org/10.7203/sagvntvm.49.10025

Costa García, J. M. (2016): «Presencia militar romana en La Chana (Castrocalbón, León)». Nailos, 3: 4785.

Costa García, J. M.; Fonte, J.; Menéndez Blanco, A.; González Álvarez, D.; Gago Mariño, M.; BlancoRotea, R. y Álvarez Martínez, V. (2016): «Roman military settlements in the northwest of the Iberian Peninsula. The contribution of historical and modern aerial photography, satellite imagery and airborne LiDAR». Newsletter of the Aerial Archaeology Research Group, 52: 43-51.

Crew, P. y Musson, C. (1996): Snowdonia from the Air. Patterns in the Landscape Snowdonia National Park Authority/ RCAHMW.

Čučković, Z. (2016) «Advanced viewshed analysis: a Quantum GIS plug-in for the analysis of visual landscapes». Journal of Open Source Software, 4(1). https://doi.org/10.21105/joss.00032

Currás, B. X.; Ruiz del Árbol, M.; Sánchez-Palencia, F. J.; Orejas, A. y Romero, D. (2015): «Ancient landscapes of north-western Iberia: historical aerial photographs and the interpretation of Iron Age and Roman territories», V. Ivanišević, T. Veljanovski, D. Cowley, G. Kiarszys, I. Bugarski, Recovering Lost Landscapes. Beograd, Institute of Archaeology: 67-78.

Davies, J. L. y Jones, R. H. (2006): Roman Camps in Wales and the Marches. Cardiff, University of Wales Press. 
Didierjean, F. ; Morillo, A. y Petit-Aupert, C. (2014): «Traces des guerres, traces de paix armée: l'apport de quatre campagnes de prospection aérienne dans le nord de l'Espagne», F. Cadiou y M. NavarroCaballero (eds.), La guerre et ses traces. Conflits et sociétés en Hispanie à l'époque de la conquête romaine (IIIe-Ier s. a.C.). Bordeaux, Ausonius: 149-179.

Driver, T.; Musson, C.; Leighton, D. y Crew, P. (1997): «Llyn Hiraethlyn». Britannia, 27: 397-399.

Fernández Ochoa, C.; Morillo, A. y Gil Sendino, F. (2012): «El Itinerario de Barro. Cuestiones de autenticidad y lectura». Zephyrus, LXX: 151-179.

García Marcos, V. (2002): «Novedades acerca de los campamentos romanos de León», A. Morillo (ed.), Arqueología Militar Romana en Hispania. Anejos de Gladius 5. Madrid, Polifemo y CSIC: 167-212.

Hesse, R. (2010): «LiDAR-derived Local Relief Models. A new tool for archaeological prospection». Archaeological Prospection, 17: 67-72. https://doi. org/10.1002/arp.374

Hinz, H. (1984): «Römische Übungslager in Veen, Kr. Moers», Beiträge zur Archäologie der römischen Rheinlands 4. Köln, Rheinland: 371-379.

Horn, H. G. (1987): Die Römer in Nordrhein-Westfalen. Stuttgart, Theiss.

Jarrett, M. G. y Nash-Williams, V. E. (1969): The Roman Frontier in Wales. Cardiff, University of Wales Press.

Johnston, M. (2003): «Excavations at Monk's Cross». Yorkshire Archaeology Today, 5: 1-3.

Jones, R. F. J. (1976): «The Roman military occupation of North-West Spain». Journal of Roman Studies, 66: 45-66. https://doi.org/10.2307/299779

Jones, R. H. (2011): Roman Camps in Scotland. Edinburgh. Society of Antiquaries of Scotland.

Jones, R. H. (2012): Roman Camps in Britain. Gloucestershire. Amberley Pub.

Jones, R. H. (2017): «What is a Roman camp?», N. Hodgson, P. Bidwell y J. Schachtmann (eds.), Roman Frontier Studies 2009. Proceedings XXI Limes Congress. Oxford, Archaeopress Roman Archaeology, 25: 521-530.

Le Roux, P. (1982): L'Armée romaine et l'organisation des provinces ibériques d'Auguste a l'invasion de 409. Paris, De Boccard.

Loewinsohn, E. (1965): «Una calzada y dos campamentos romanos en el Conventus Asturum». Archivo Español de Arqueología, 38: 26-49.

Lynch, F. (1995): «Tomen y Mur and Dolddinas Practice Camps», A Guide to Ancient and Historic Wales. Gwynedd, HMSO: 106-109.

Martín Hernández, E.; Martínez Velasco, A.; Díaz Alonso, D.; Muñoz Villarejo, F. y Becares Rodríguez, L. (2020): «Castrametación romana en la Meseta Norte hispana: nuevas evidencias de recintos militares en la vertiente meridional de la cordillera Cantábrica (provincias de Burgos y
Palencia)». Zephyrus, LXXXVI: 143-164. https:// doi.org/10.14201/zephyrus202086143164

Martínez González, C. (1874): Memoria explicativa de varias calzadas romanas en León. Manuscrito inédito de la Real Academia de la Historia.

Moreno Gallo, I. (2011-2017): «Identificación y descripción de la vía romana de Astogra a León, De Asturica a Legio VII Gemina», Vías Romanas de Castilla y León Disponible en: http://www. viasromanas.net/pdf/06_Via_romana_Astorga_a Leon.pdf

Morillo, A. (1991): «Fortificaciones campamentales de época romana en España». Archivo Español de Arqueología 64: 135-90

Morillo, A. (2002): «Conquista y estrategia: el ejército romano durante el periodo augusteo y julio-claudio en la región septentrional de la Península Ibérica», A. Morillo (coord.): Arqueología Militar Romana en Hispania. Anejos de Gladius 5. Madrid, CSICPolifemo: 67-93.

Morillo, A. (2008): «Criterios de identificación de campamentos romanos en España». Saldvie, 8: 73-93.

Morillo, A. (2012): «Investigación científica y arqueología urbana en la ciudad de León», J. Beltrán y O. Rodríguez (eds.), Hispaniae urbes. Investigaciones arqueológicas en ciudades históricas. Sevilla, Universidad de Sevilla: 211-256.

Morillo, A.; Adroher, A.; Dobson, M. y Martín Hernández, E. (2020): «Constructing the archaeology of the Roman conquest of Hispania: new evidence, perspectives and challenges», Journal of Roman Archaeology, 33: 36-52. https://doi.org/10.1017/ s1047759420000902

Morillo, A. y Durán Cabello, R. (2017): «Territorios militares en Hispania: nuevas perspectivas». Gerión 35(2): 511-536. https://doi.org/10.5209/geri.59922

Morillo, A. y García Marcos, V. (2006): «Legio (León). Introducción histórica y arqueológica», M. ${ }^{\mathrm{a}} \mathrm{P}$. García-Bellido (coord.), Los campamentos romanos en Hispania (27 a. C.-192 d. C.). El abastecimiento de moneda. Anejos de Gladius 9. Madrid, Madrid, Polifemo y CSIC: 225-243.

Morillo, A. y García Marcos, V. (2020): «Un ejemplo particular de comunidad cívica en territorio militar: el vicus de Ad Legionem (Puente Castro, León)», E. Ortiz de Urbina (ed.), Memoria Civitatum. Ciudadanía, ciudad y comunidad cívica. Sevilla, Universidad de Sevilla: 239-263.

Morillo, A.; García Marcos, V.; Salido Domínguez, J. y Durán Cabello, R. (2018): «El vicus militar de Ad Legionem (Puente Castro, León). Las intervenciones arqueológicas de los años 2000-2001». Spal 27, 1: 145-183. https://doi.org/10.12795/ spal.2018i27.06

Morillo, Á. y Sala Sellés, F. (2019): «The Sertorian Wars in the conquest of Hispania: from data to archaeological assesment», A. P. Fitzpatrick y C. Haselgrove (eds.), The Archaeology of Caesar in 
Britain and Gaul. New archaeological perspectives. Oxford-Philadelphia, 49-72.

Musson, C. (1994): Wales from the Air, Patters of Past and Present. Aberystwyth, Royal Commission on the Ancient and Historical Monuments of Wales.

Opitz, R. y Cowley, D. C. (eds.) (2012): Interpreting Archaeological Topography: Lasers, 3D Data, Observation, Visualisation and Applications. Oxford, Oxbow Books.

Orejas, A. (1995): Del “marco geográfico" a la Arqueología del paisaje. La aportación de la fotografía aérea. Madrid. CSIC.

Orejas, A. (2011): «Las formas de los paisajes. Lo visible y lo invisible», V. Mayoral y S. Celestino (eds.), Tecnologías de Información Geográfica y análisis arqueológico del territorio. Actas del V Simposio Internacional de Arqueología de Mérida, Anejos de Archivo Español de Arqueología, LIX. MadridMérida, CSIC: 601-615.

Orejas, A. y Sánchez-Palencia, F. J. (1999): «Arqueología de la Conquista del Noroeste de la Península Ibérica», R. de Balbín y P. Bueno (eds.), II Congreso de Arqueología Peninsular (Zamora, del 24 al 27 de septiembre de 1996). Tomo IV: Arqueología Romana y Medieval. Alcalá de Henares -Zamora, Fundación Rei Afonso Henriques: 23-37.

Orejas, A.; Sánchez-Palencia, F. J.; Beltrán, A.; Ron, J. A.; López, L. F.; Currás, B. X.; Romero, D.; Zubiaurre, E.; Pecharromán, J. L. y Arboledas, L. (2015): «Conquista, articulación del territorio y explotación de recursos en el límite entre el convento lucense y el de los astures (Proyecto IVGA)», J. Camino Mayor, E. Peralta labrador y J. F. Torres Martínez (coords.), Las Guerras Astur-Cántabras. Gijón, Ayuntamiento de Gijón: 247-259.

Orejas, A.; Sánchez-Palencia, F. J.; Currás, B. X.; Ron, J. A. y López, L. F. (2019): "Campamentos militares durante la primera ocupación romana del noroeste de la península Ibérica», B. Vallori Márquez, C. Rueda Galán y J. P. Bellón Ruiz (eds.), Accampamenti, guarnigioni e assedi durante la Seconda Guerra Punica e la conquista romana (secoli III-I a. C.): prospettive archeologiche. Roma, Quasar: 97- 111.

Phang, S. E. (2008): Roman military Service. Ideologies of Discipline in the Late Republic and Early Principate. Cambridge, Cambridge University Press.
Philpott, R. A. (1998): «New Evidence from Aerial Reconnaissance for Roman Military Sites in Cheshire». Britannia, 29: 342-353. https://doi. org/10.2307/526830

Picarreta, F. (1987), Manuale di fotografia aerea: uso archeologico. Roma, L'Erma di Bretschneider.

Rodríguez Fernández, L. R. y Heredia, N. (2005): Mapa Geológico de España. Escala 1:50.000. Hoja 161. León. IGME. Madrid.

Sánchez-Palencia, F. J. (1986): «El campamento romano de Valdemeda, Manzaneda (León). Ocupación militar y explotación aurífera en el NW peninsular». Numantia: 227-235.

Sánchez-Palencia, F. J. y Currás, B. X. (2015): «Campamentos romanos en zonas mineras del cuadrante noroeste de la Península Ibérica», J. Camino-Mayor, E. Peralta-Labrador y J. F. Torres-Martínez (coords.), Las Guerras Astur-Cántabras. Gijón, Ayuntamiento de Gijón: 273-283.

Schnurbein, S. von (2006): «Camps d'étape et camps d'entraînement», en M. Reddé (dir.), Les fortifications militaires, L'architecture en Gaule romaine, DAF 100. Bordeaux: Ausonius: 136-139.

Scollar, I. (1965): Archäologie aus der Luft, Arbeitsergebnisse der Flugjahre 1960 und 1961 im Rheinland. Düsseldorf, Rheinland.

Scollar, I. y Andrikopoulou-Strack, N. (1984): «Römische übungslager süldlich von Xanten im Luftbild. Einige technische Einzelheiten», Beiträge zur Archäologie der römischen Rheinlands 4. Köln, Rheinland: 381-390.

St. Joseph, J. K. (1977): «Air Reconnaissance in Roman Britain, 1973-76». Journal of Roman Studies, 67: 125-161. https://doi.org/10.2307/299924

Számadó, E. y Borby, L. (2003): «Brigetio temporary Camps», Z. Visy (ed.), The Roman Army in Pannonia. An archaeological Guide of the Ripa Pannoni$c a$. Budapest, Teleki László Foundation: 78-79.

Visy, Z. (2003): The Ripa Pannonica in Hungary. Budapest, Akadémiai Kiadó.

Welfare, H. y Swan, V. (1995): Roman Camps in England: The Field Archaeology. London, RCHME.

Wilson, D. R. (1982): Air photo interpretation for archaeologist. London, Batsford.

Zakšek, K.; Oštir, K. y Kokalj, Z. (2011): «Sky-View Factor as a Relief Visualization Technique». Remote Sensing, 3: 398-415. https://doi.org/10.3390/ rs3020398 
